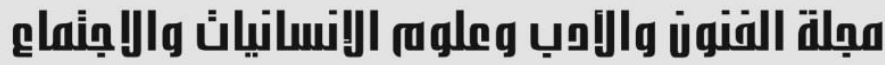

\section{صيغة (أتخذ) ومجالاتها الدلالية في القرآن الكريم}

\author{
أ.م.د. إيمان صالح مهدي \\ قسم المخطوطات ـ مركز إحياء التراث العزئ العلمي العربي - جامعة بغداد ـ العراق \\ mahdi.eiman@yahoo.com الايميل:
}

طبق البحث فكرة الحقل الدلالي على صيغة صرفيه وردت في القرآن الكريم وهي صيغة (اتخذ) متناو لا الآيات الكريمة التي وردت فيها ،مقسمة على الأزمنة الثلاثة ، عارضا تفسير العلماء الأجلاء لتلك الآيات ،مستعينا بهذه التفاسير على اعطاء العنوان المناسب للمجال الذي ظهرت فيه الصيغة ، مرتكز ا على سياقات ورودها لما لهذه السياقات من اعتبار في تحديد دلالة اللفظة ،فكانت مجالاتها في البر و الإحسان كما كانت في العقوق والإساءة ولكل من هذين المجالين العامين مجالات فرعية خاصة تنضوي تحتهما ، إن هذه النظرية لم تكن بعيدة عن ذهن لغو يينا العرب و أصحاب المعجمات ،ومن ألف في غريبي القرآن و الحديث الشريف ، إلا أنها لم تتأصل إلا في لهي الوقت الحاضر، هذه النظرية يمكن تطبيقِا على مستويات اللغة كلها النحوية ،والصرفية، والصوتية ، و المعجمية ، بل حتى من ناحية المهمل والمستعمل من الألفاظ ، و القديم والجديد ،وكل ما يمكن أن ينضوي تحت

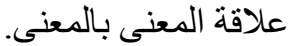
الكلمات المفتاحية: صيغ القرآن الكريم، المجال الدلالي، القران الكريم. 


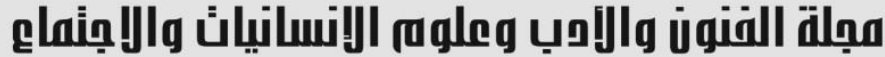

\section{The Word (Itakhatha) and its Semantic in Holy Quran}

\author{
Assist. Prof. Dr. Iman Salih Mahdi \\ Manuscript Department, Center of Revival Heritage - Baghdad University - Iraq \\ Email: mahdi.eiman@yahoo.com
}

\begin{abstract}
This search applied an idea of Semantic field on syntactic term Mentioned in Quran which is (itakhatha), it had taken holy ( ayat) that contained this word, divided in to three times, and show scientific in terpretation For these (ayat) to give suitable title for this term its other Semantic deals to goodness as will as deals to badness in addition to many branch meanings. This phenomena dose not be for from Arabic linguistics who

The writing about Quran and hadiths ,and it may be applied in all stages of languages ,syntactic ,semantic, as it may be appeared the Field of usage and neglected words and in every term contained meaning with.
\end{abstract}

Keywords: term of holy Quran, holy Quran, semantically field. 


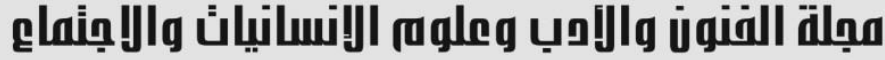

Journal of Arts, Literature, Humanities and Social Sciences www.jalhss.com

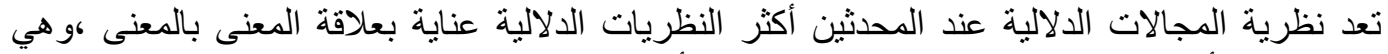

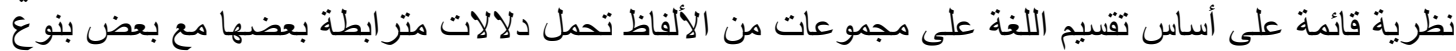

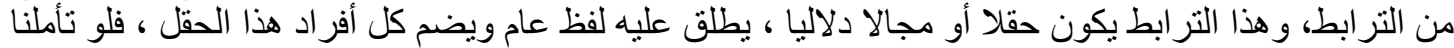

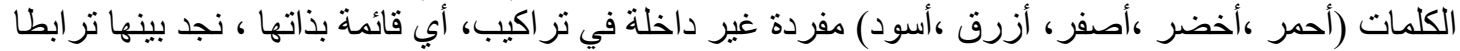

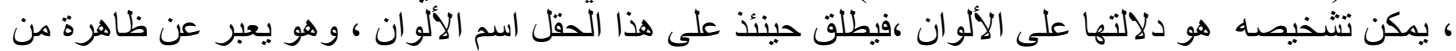

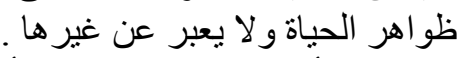
ويعرّف أولمان الحقل الدلالي بأنه " قطاع متكامل منامل من المادة اللغوية يعبر عن مجال معين من الخبرة "

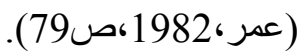

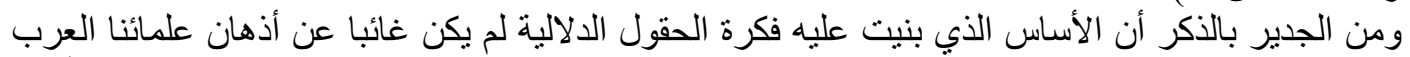

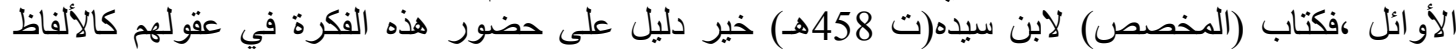

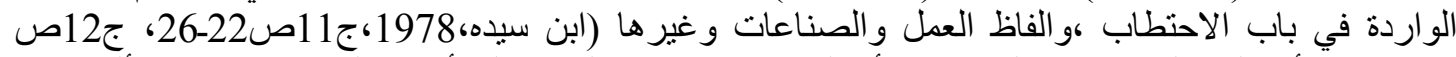

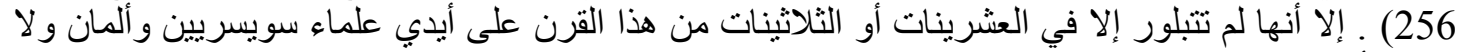

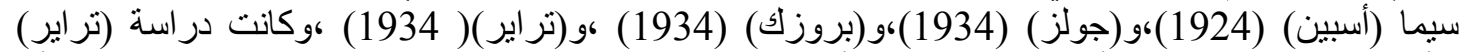

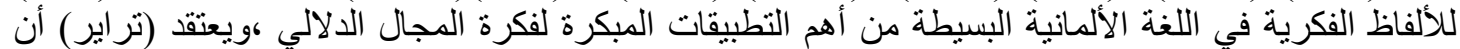

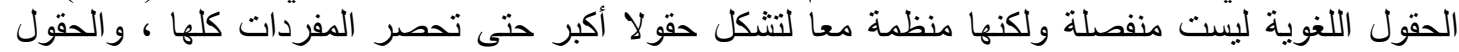

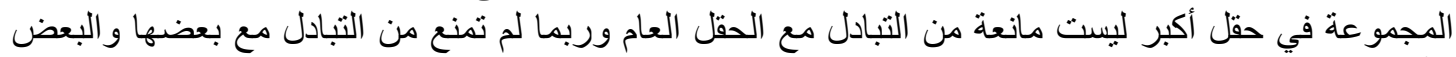

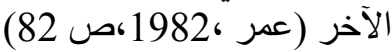

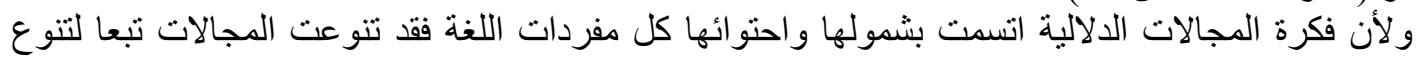

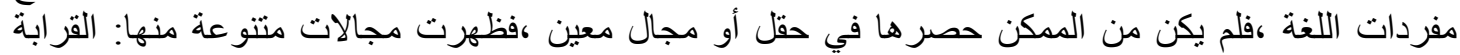
،و الدين ،و الألوان، و ألفاظ الأصوات ،وات ،وقع الأثاث ،و التجارة ،و غير ها.

$$
\text { وقسم أولمان مفردات اللغة على ثلاثة حقول أو مجالات هي: }
$$

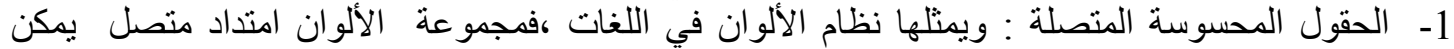

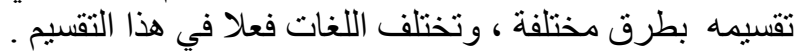

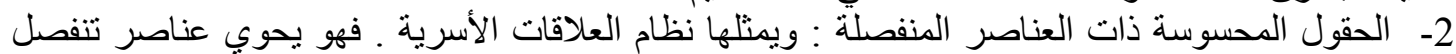

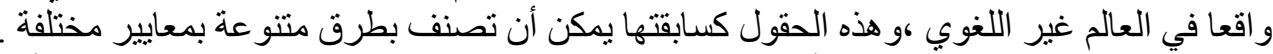

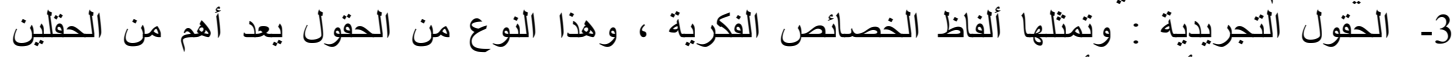

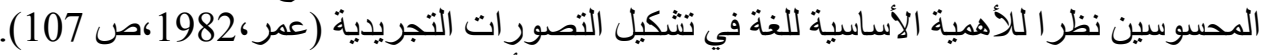

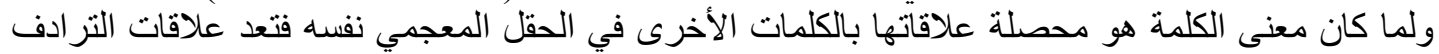

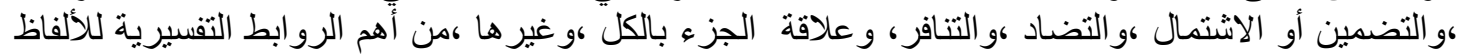

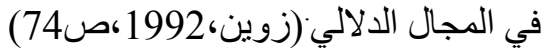
ويتفق أصحاب نظرية المجالات الدلالية على جملة مبادئ ،هي :

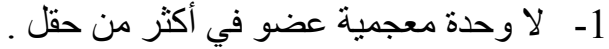
2-

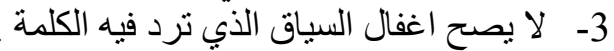

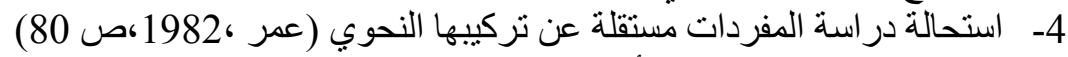

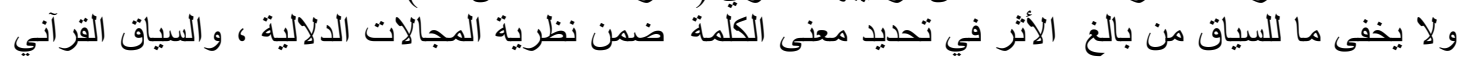

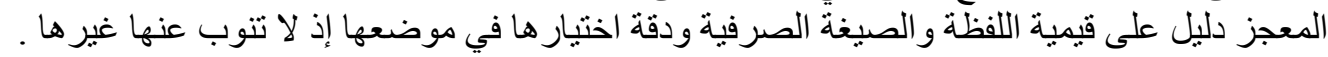

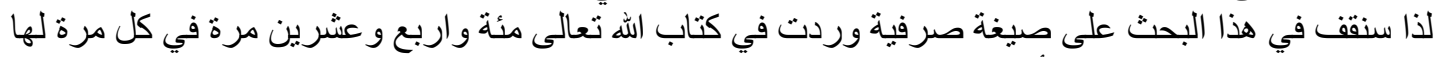

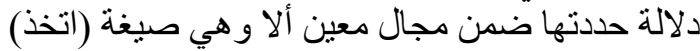

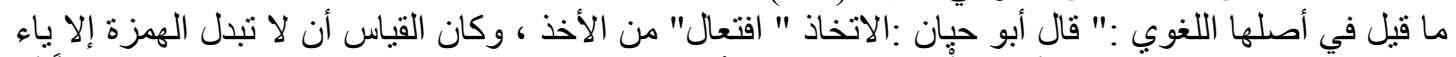

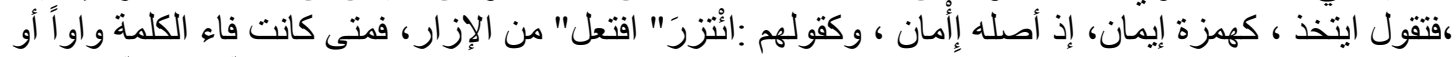

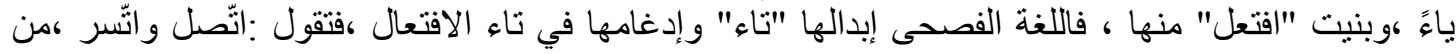




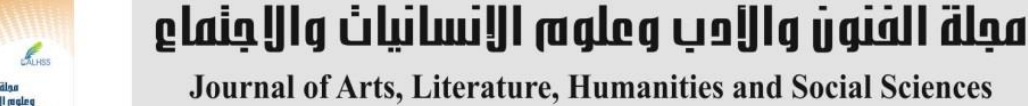
www.jalhss.com

الوصل و اليسر ـ فإن كانت فاء الكلمة "همزة" وبنيت "افتعل" أبدلت تللك الهمزة "ياءًا و وأقررتُها ، هذا هو القياس

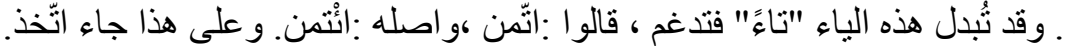

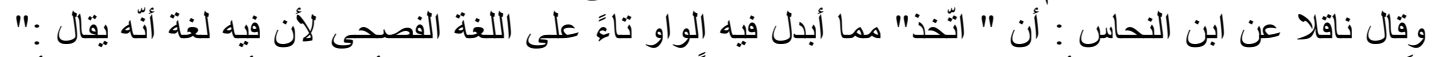

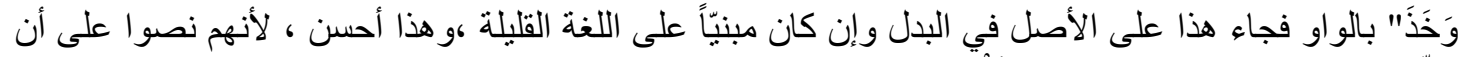

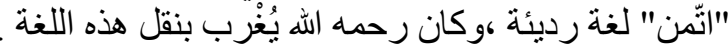

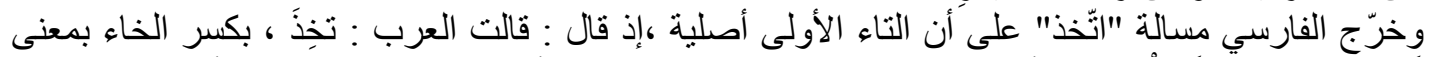

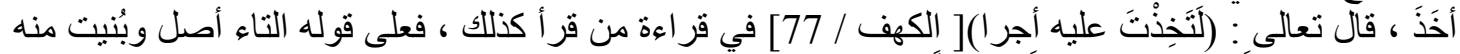

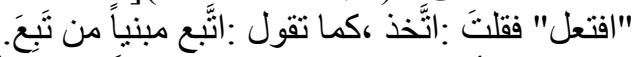

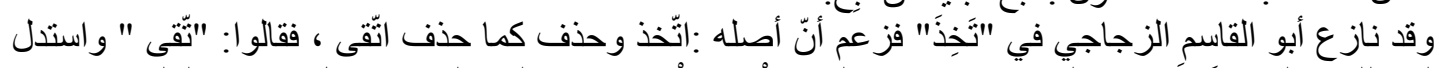

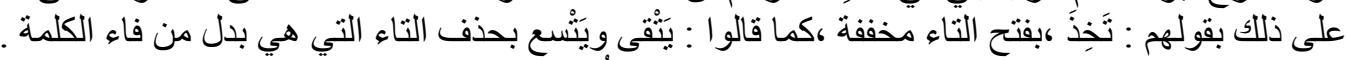

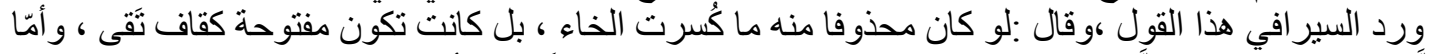

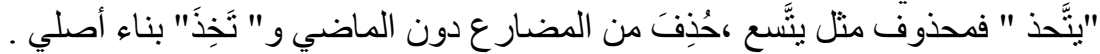

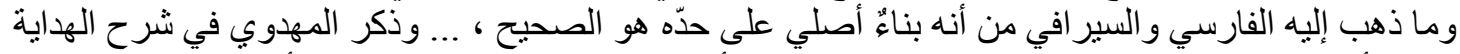

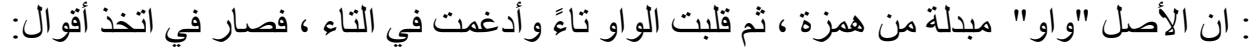

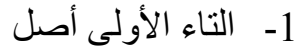

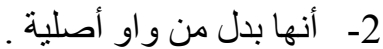

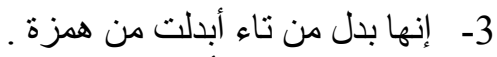

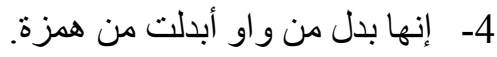

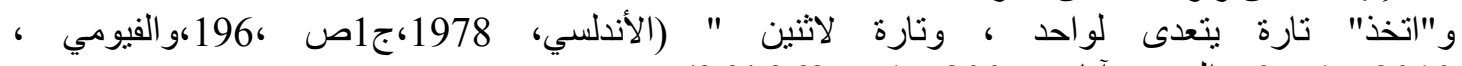

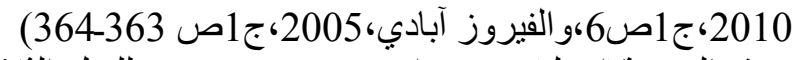

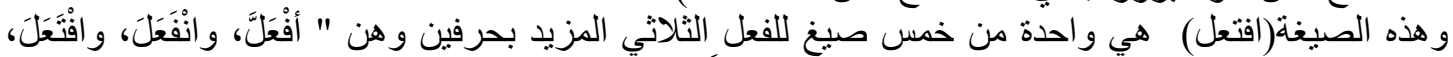

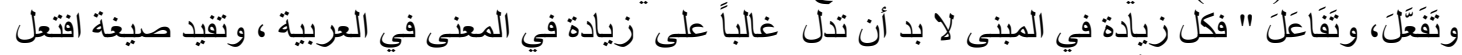

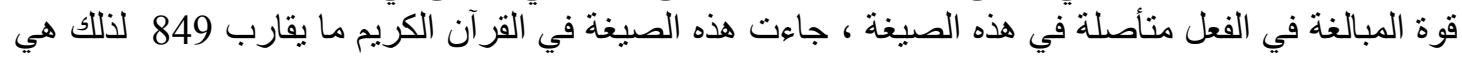

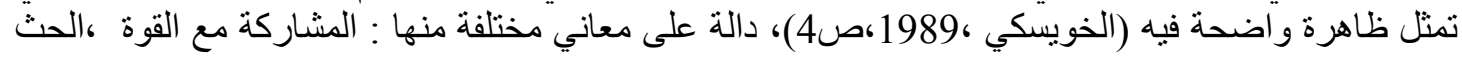

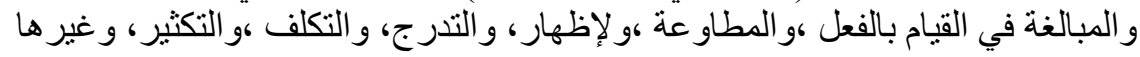

$$
\text { المجالات الدلالية التي خرجت إليها صيغة (اتخذ) }
$$

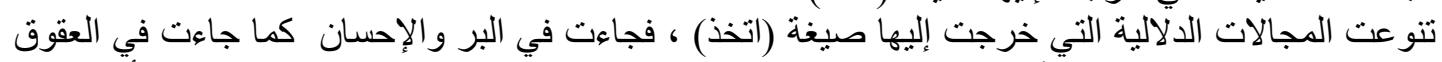

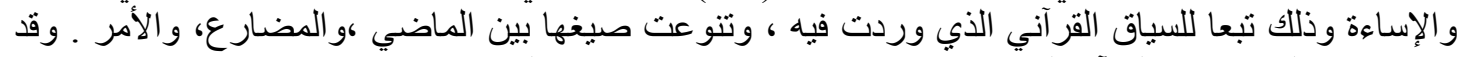

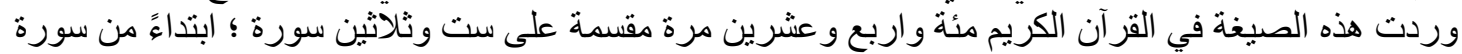

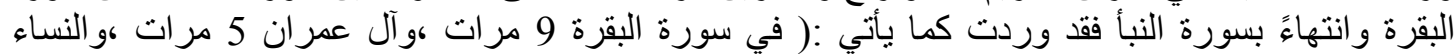

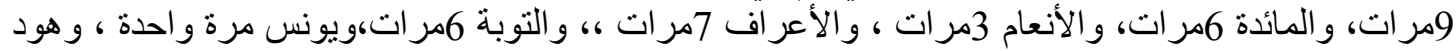

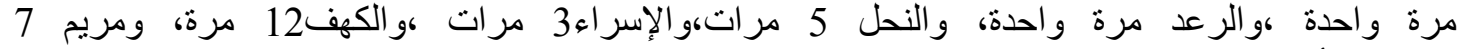

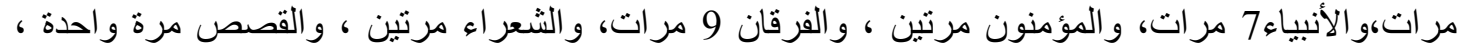

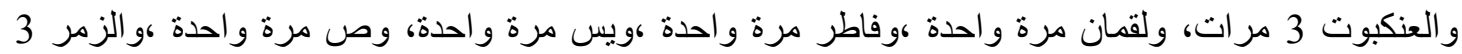

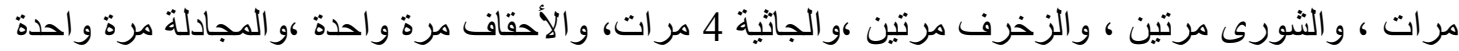

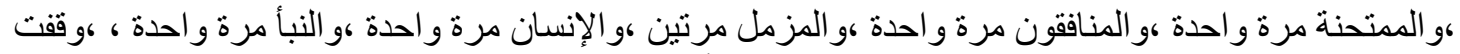

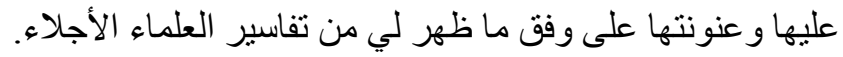




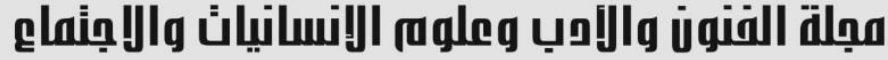

\begin{tabular}{|c|c|c|}
\hline 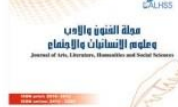 & $\begin{array}{r}\text { Journal of Arts, Liter } \\
\text { w }\end{array}$ & and Social Sciences \\
\hline$=\quad=$ & Volume (54) July 2020 & العدد (54) يوليو 2020 \\
\hline
\end{tabular}

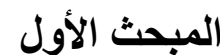

أولا : المجالات الدلالية لصيغة (اتخذ) في الزمن الماضي الدالة على البر والاحسان.

\section{المجال الأول: الاختيار

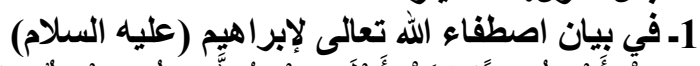

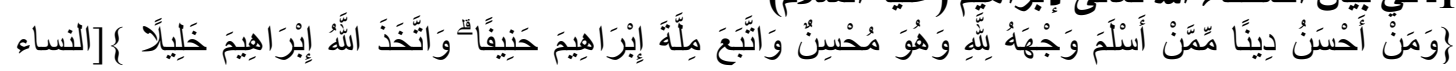

قال الزمخشري :" مجاز ا عن اصطفائه واختصاصه بكر امة تشبه كر امة الخليل عند خليله" (الزمخشري

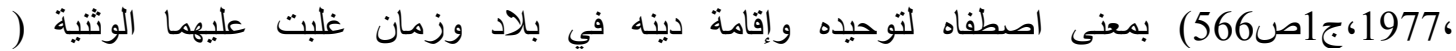

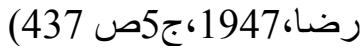

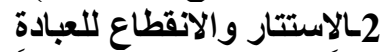

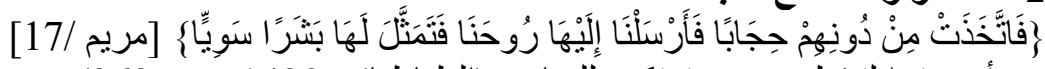

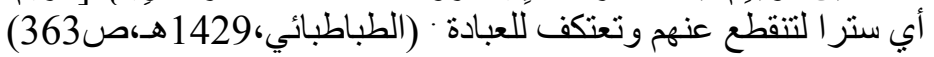

\section{المجال الثاني: التززيه}

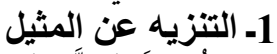

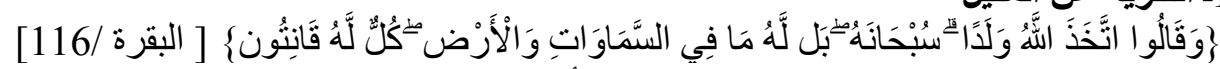

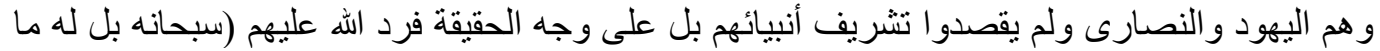

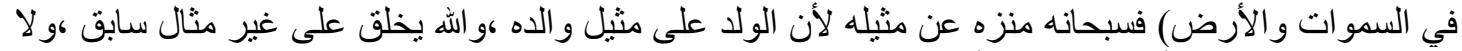

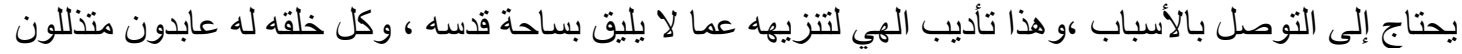

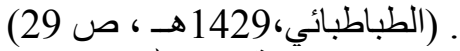

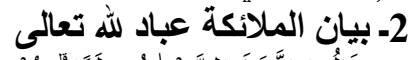

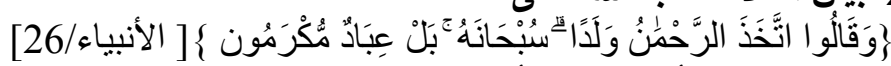

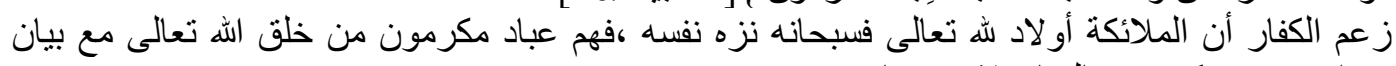

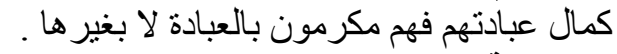

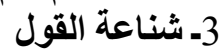

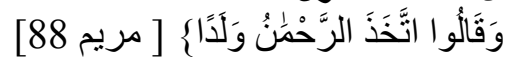

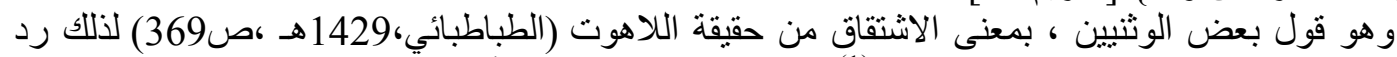

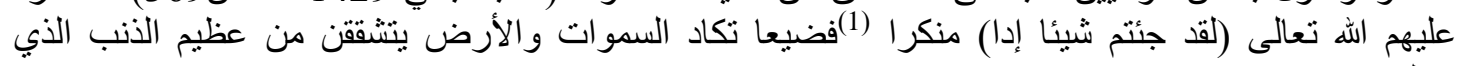

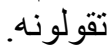

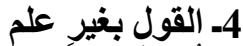

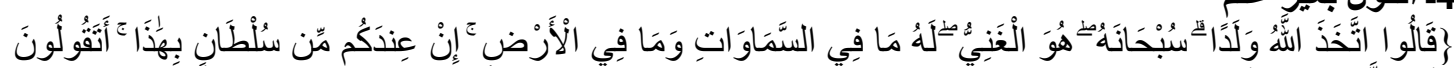

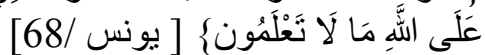

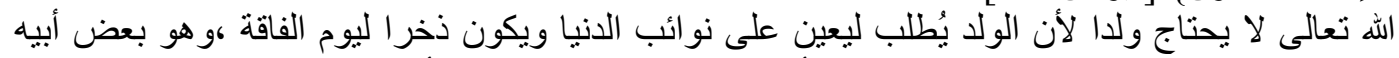

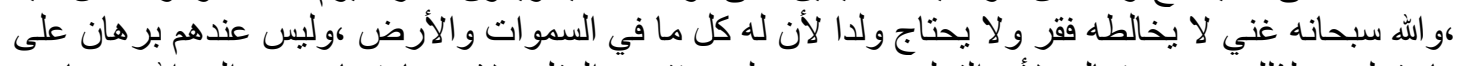

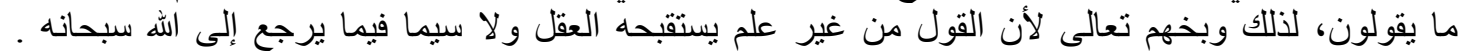

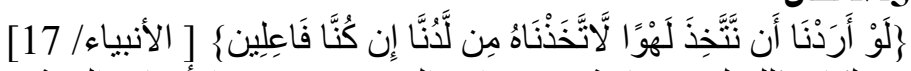

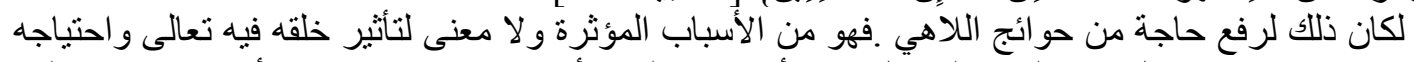

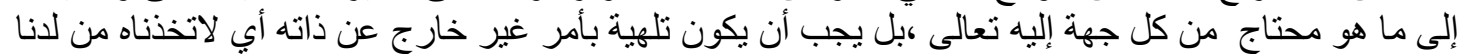

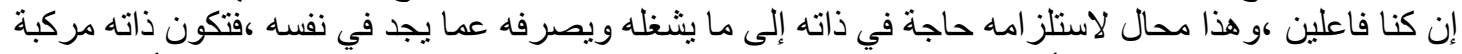

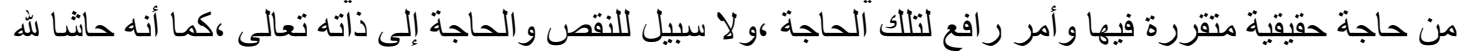

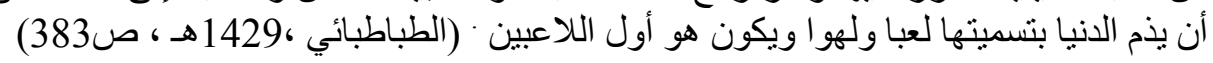




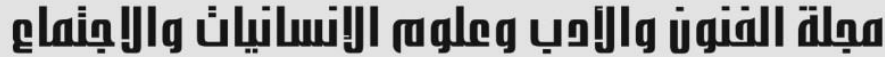

Journal of Arts, Literature, Humanities and Social Sciences
www.jalhss.com

أي مذهبا يقال سرب يسرب سربا إذا مضى لوجهاب الوبه في سفر غير بعيد ولا شاق وهي السربة فإذا كانت

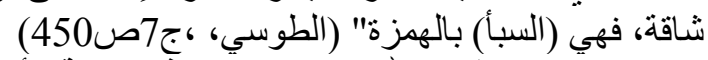

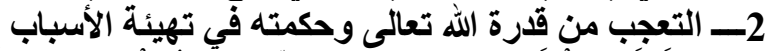

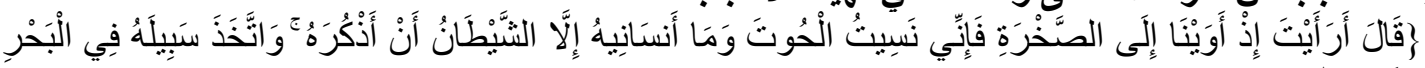

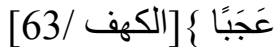

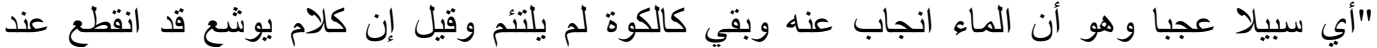

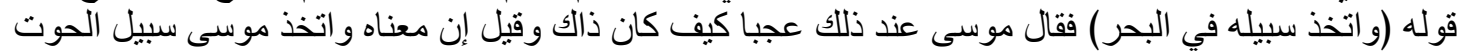

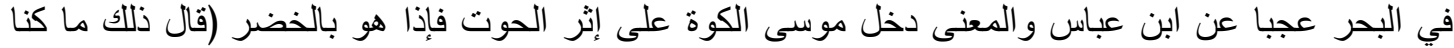

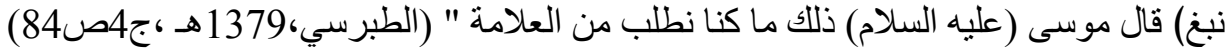

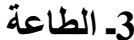

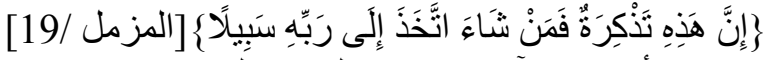

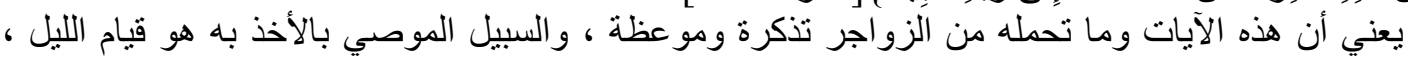

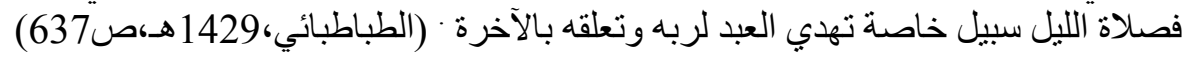

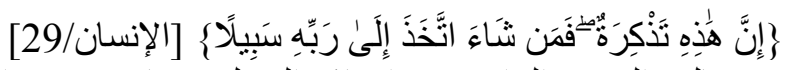

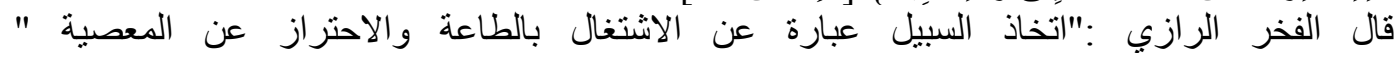

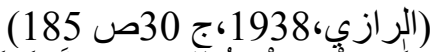

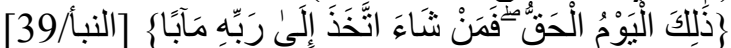

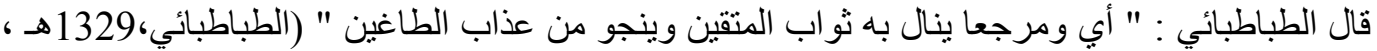

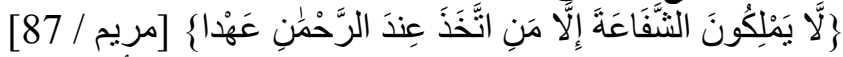

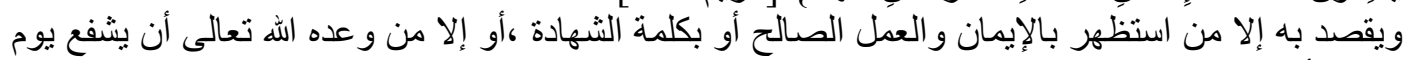

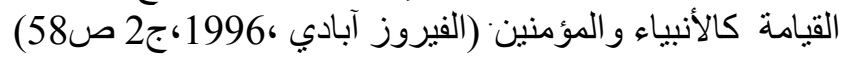

\section{المجال الخامس: الدلالة على وحدانية الله سبحانه وتعالى}

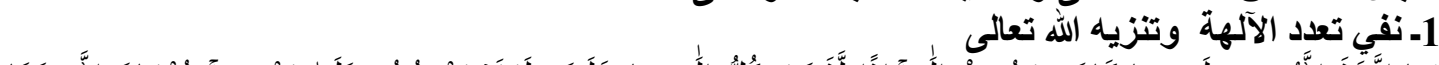

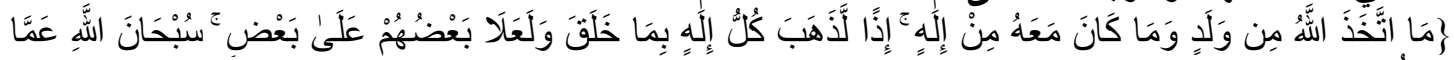

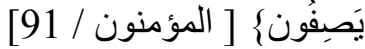

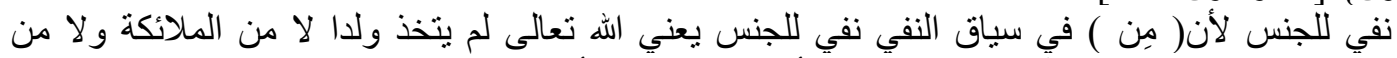

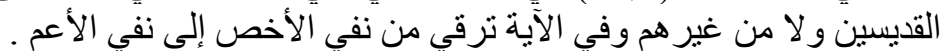
2 - 2 تأكيد نفي الثريك ]

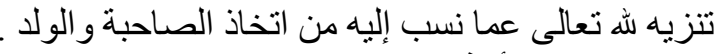

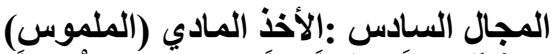

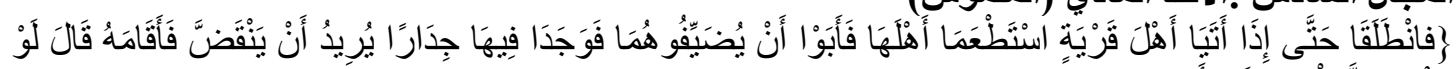

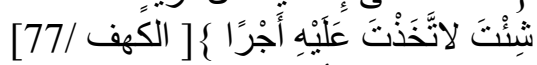
هذا مشعر بأن البناء كان بعمل غير خارف لإن فإن المعهود من أخذ الأجر، ما كان على العاديات. 


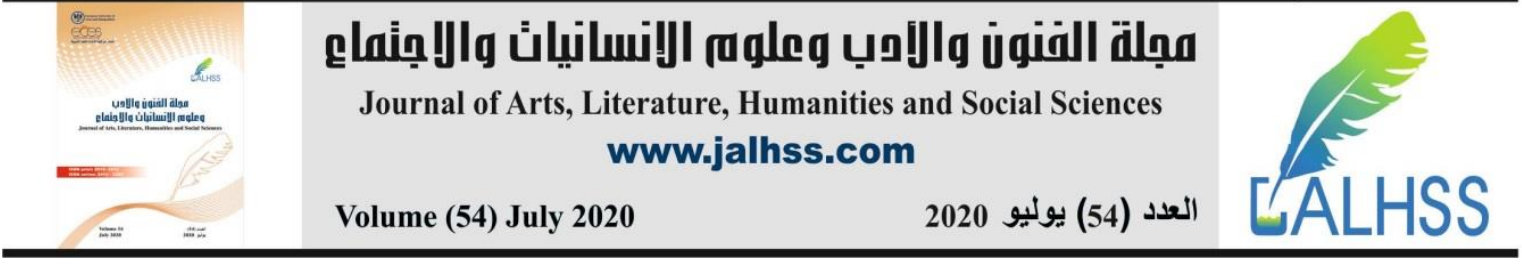

ثانياً : المجالات الالالية لصيغة (اتخذ) في الزمن الماضي الدالة على العقوق والإساءة المجال الأول :الصنع والإعداد

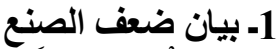

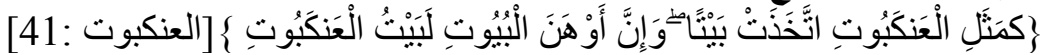

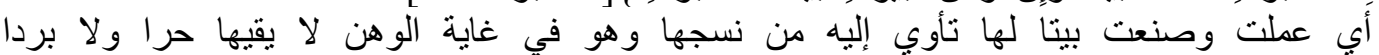

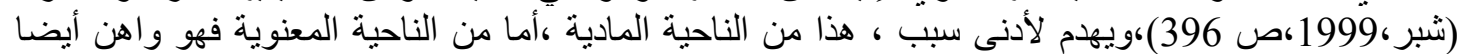

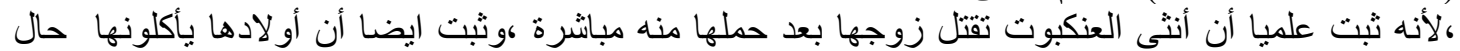

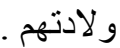
2- بيان نفاق بعض من يدعون الإسلام وكفر هم وكذبهر.

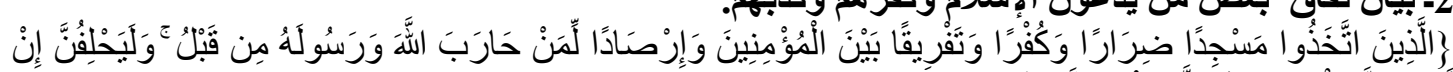

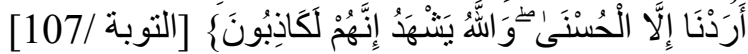

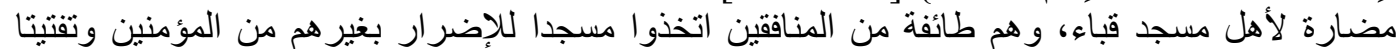

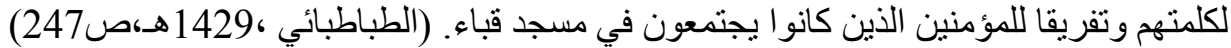

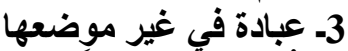

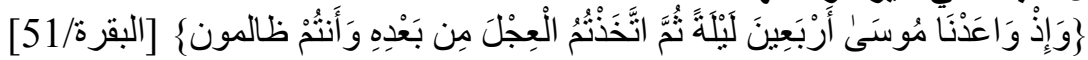

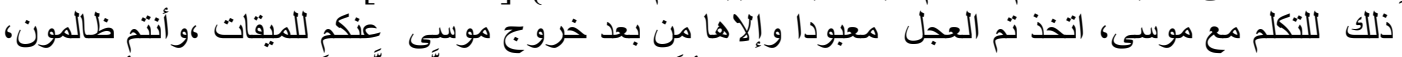

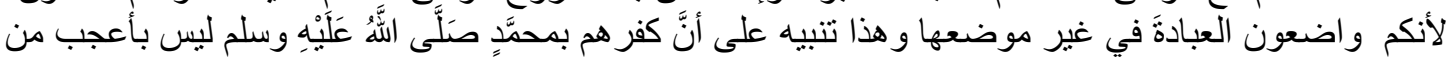

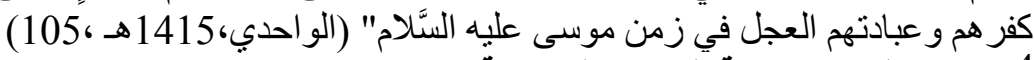

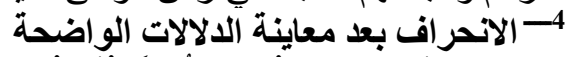

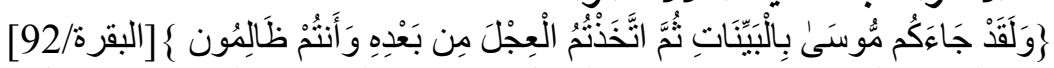

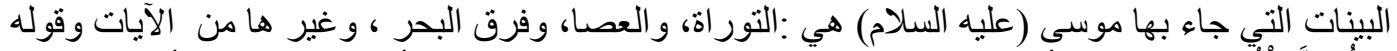

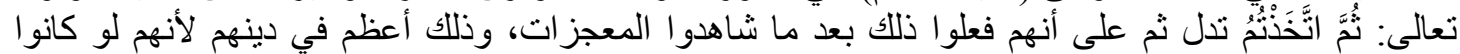

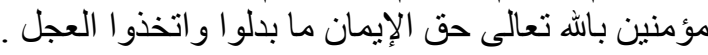

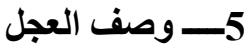

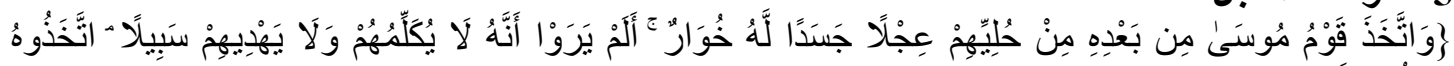
وَكَانُو انَالِلِينِ

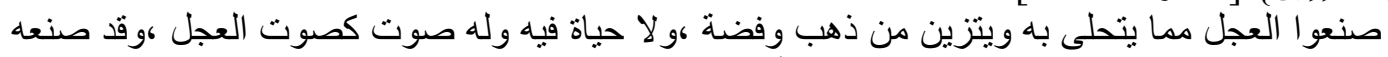

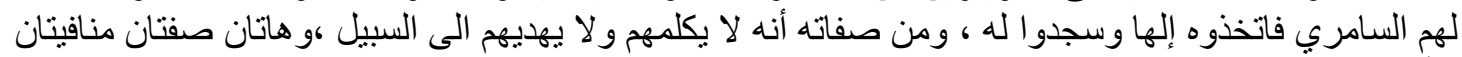

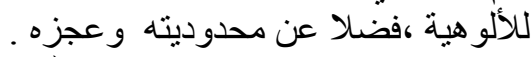

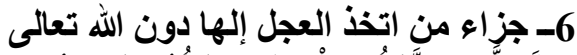

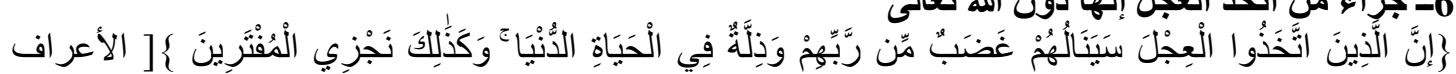

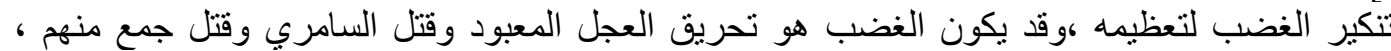

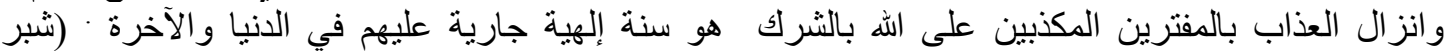
(16901999،

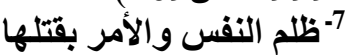

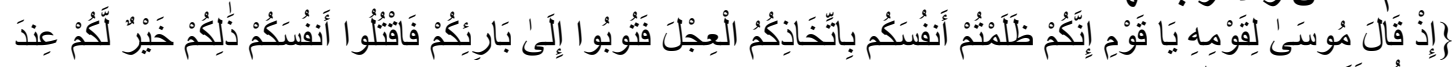

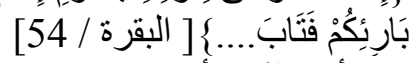

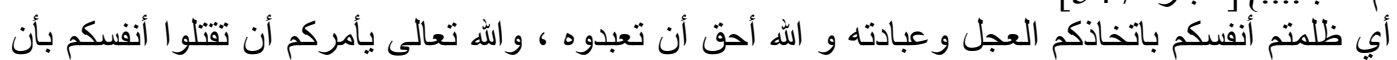

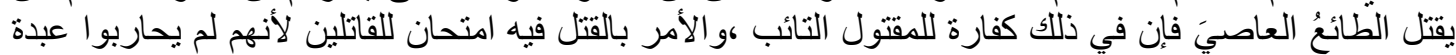

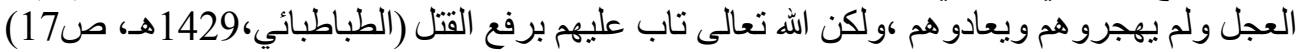

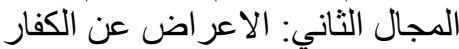

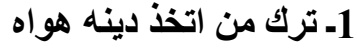




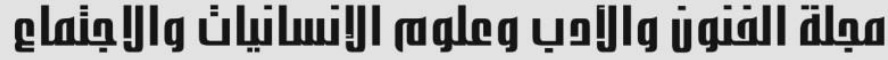

Journal of Arts, Literature, Humanities and Social Sciences www.jalhss.com

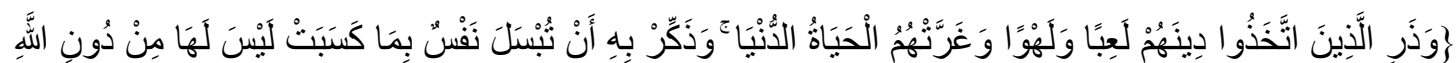

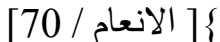

أي اتركهم فتلدينهم بما يدعو هم إليه هوى أنفسهم لعب ولهو ،و الدين الحق الذي تدعو إليه الفطرة يجب أن

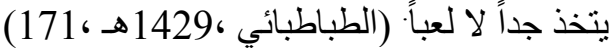

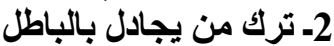

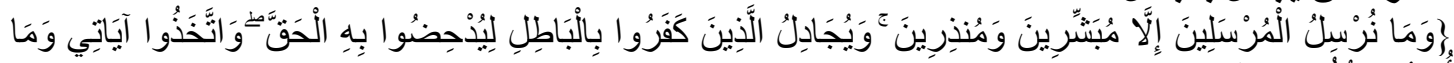

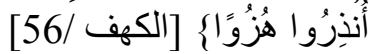

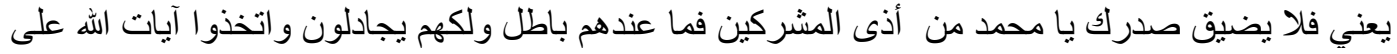

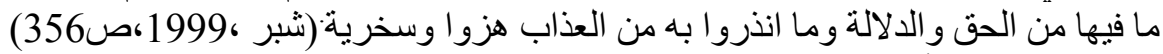

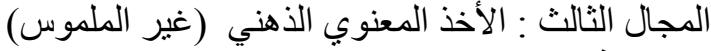

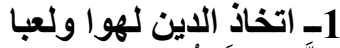

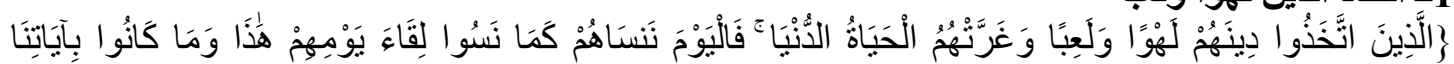

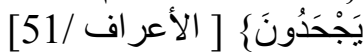

اللهو هو ما يشغل عما يهم ، و اللعب هو الفعل المأتي به لغاية خيالية غير حقيقية ـ (شبر ،1999،169) 2 - 2 الخاذ الضعيف ولياً

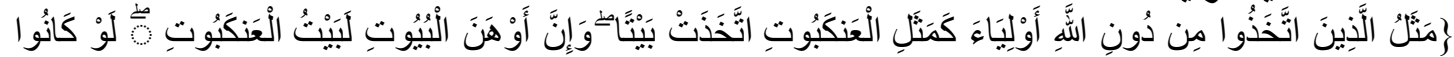

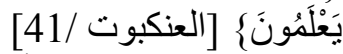

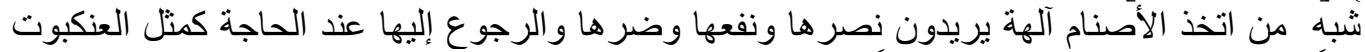

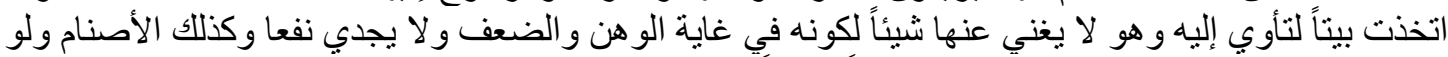

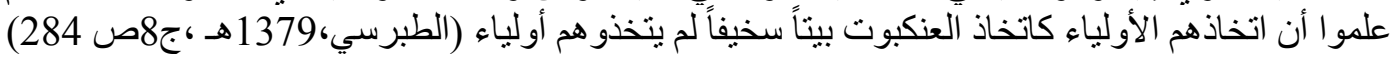
3- دفع التهم عن انفسهر

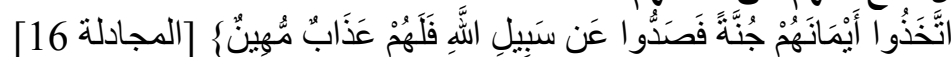

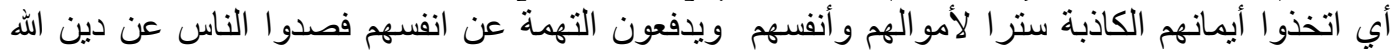

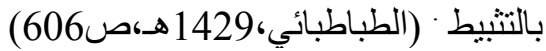
4- ت تقبيح أعمال المنافقين

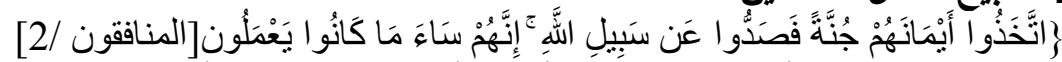

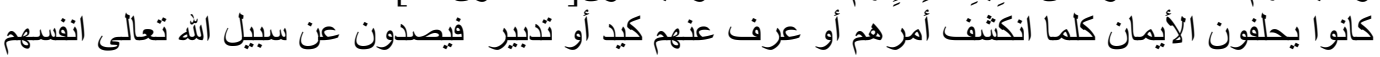

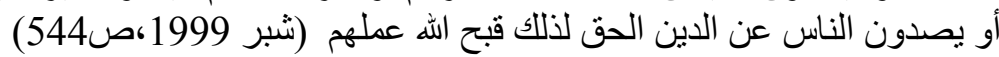

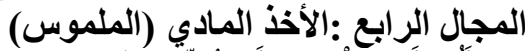

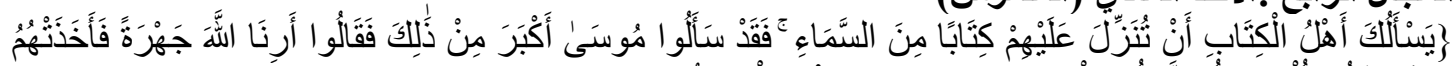

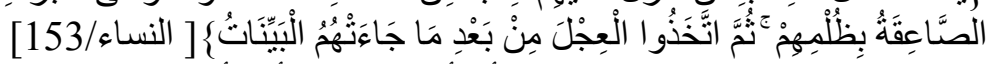

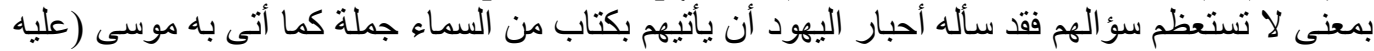

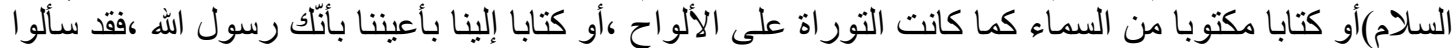

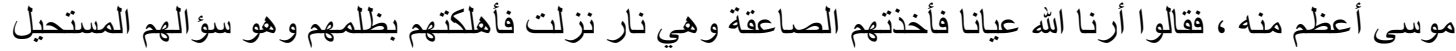

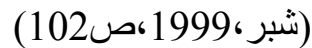
(ع) المجال الخامس : شكوى الأنبياء (ع)

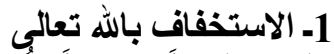

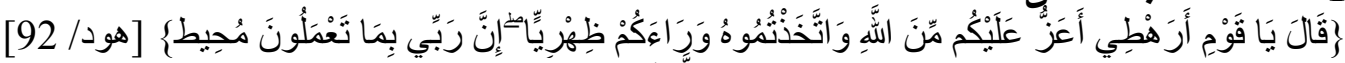

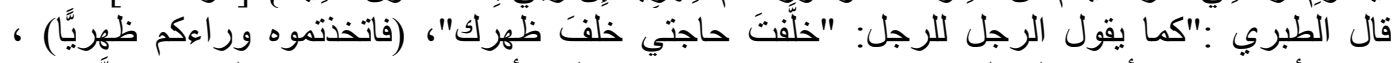

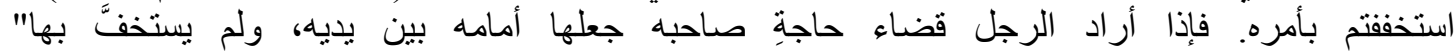

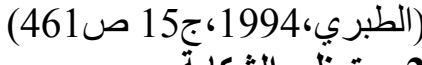

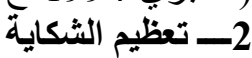

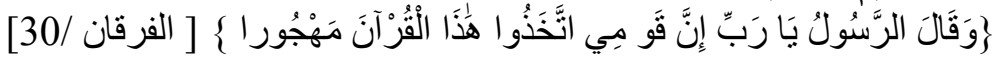




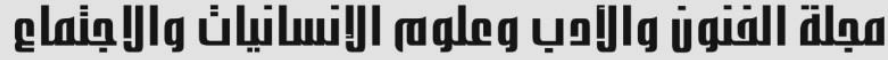

Journal of Arts, Literature, Humanities and Social Sciences www.jalhss.com

"الرسول: محمد صلى الله عليه وسلم وقومه قريش، حكى الله عنه شكو اه قومه إليه. وفي هذه الحكاية تعظيم للثكاية وتخويف لقومه لأن الأنبياء كانوا إذا التجئوا إلبه وشكوا إلبه قومهر: حلّ بهم الَّذاب ولم ينظروا"

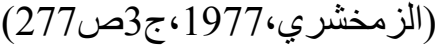
وبما أن العذاب لم يحل في الدنيا بالذين شكاهم الرسول (صلى الله عليه و آله ) فإن هذه الثكوى هي في الآخرة

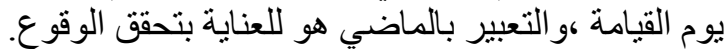
المجال السادس: : الإنهار

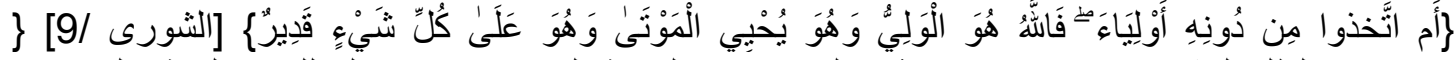

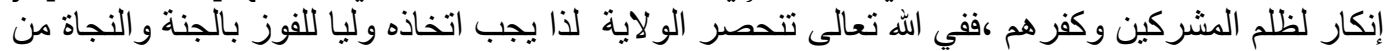

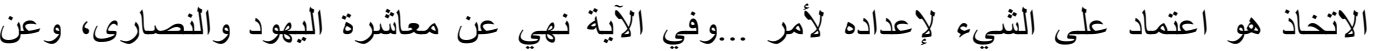

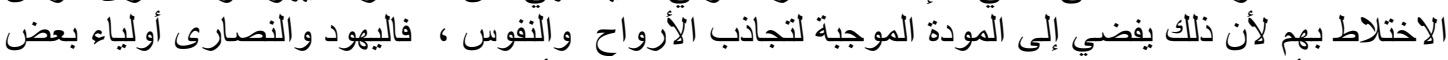

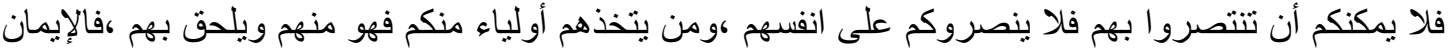

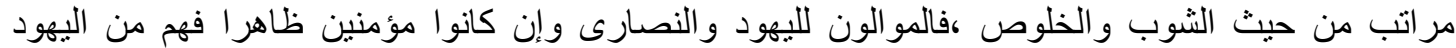

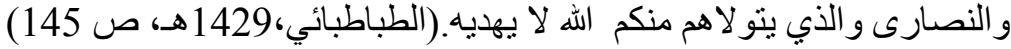

المجال السابع :وصف الكافرين وجزائهم

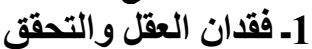

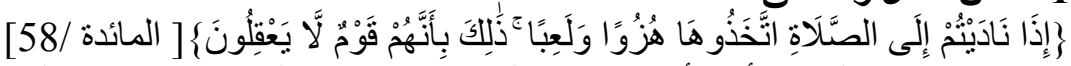

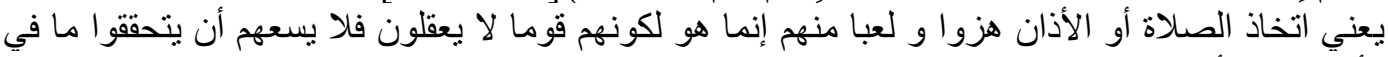

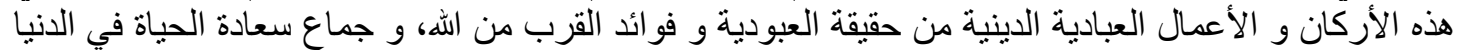

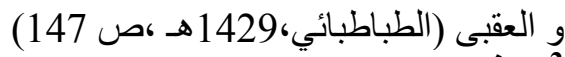

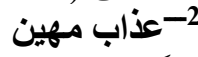

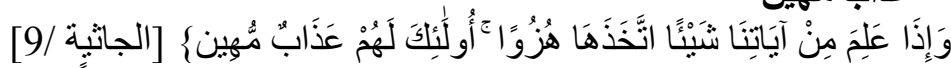

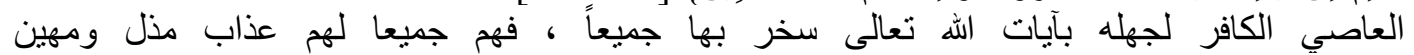

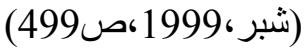

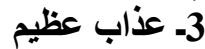

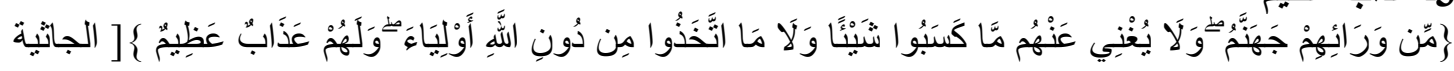

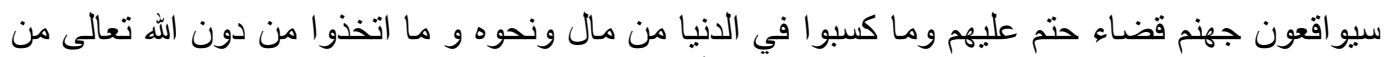

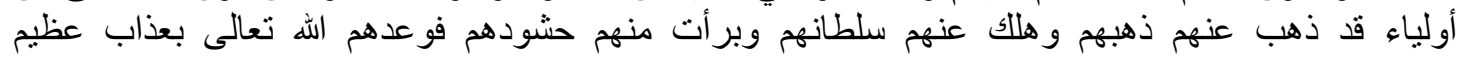

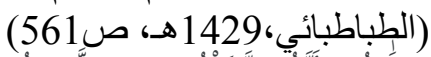

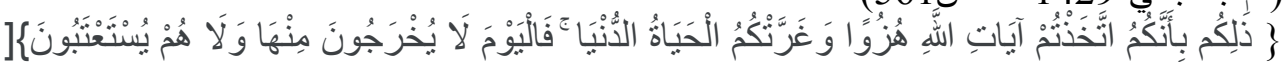

يعني ما حل بكم من عذاب اليوم هو بسبب سخريتكم من حجج الله و ادلته و وآياته التي أنزلها على الته رسوله

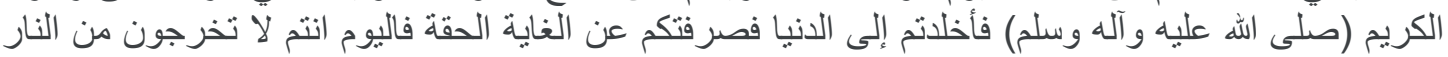

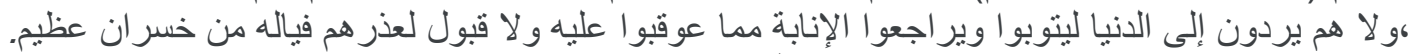

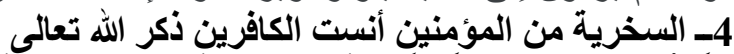

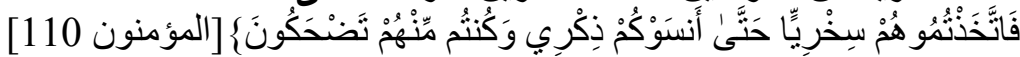

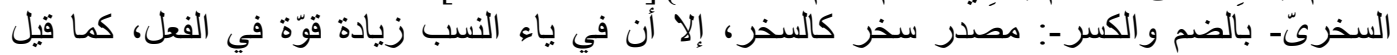

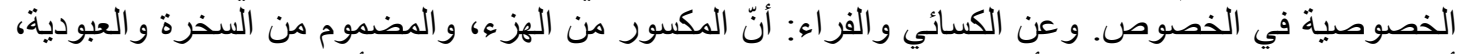

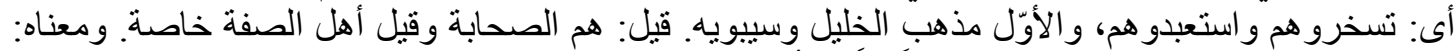

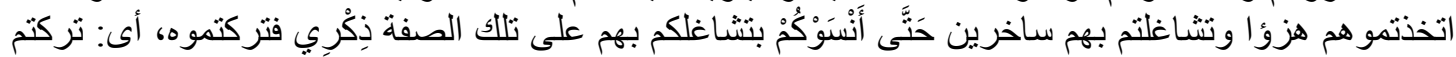




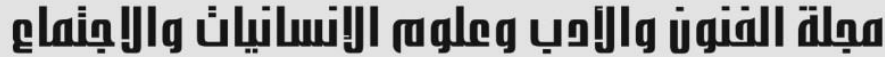

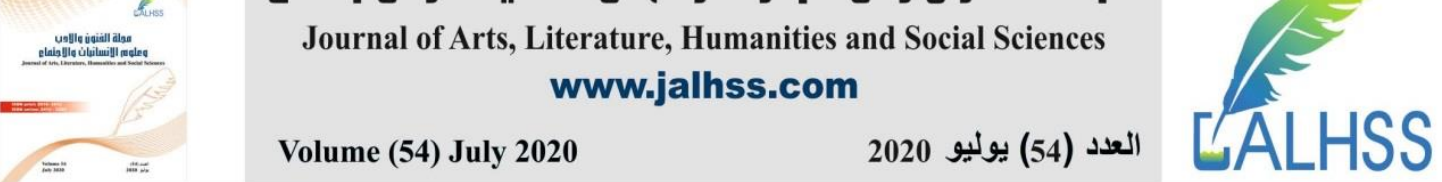

أن تذكرونى فتخافونى في أوليائى. وقرئ أَنَّهُم بالفتح، فالكسر استئناف، أى: قد فازوا حيث صبروا، فجزوا

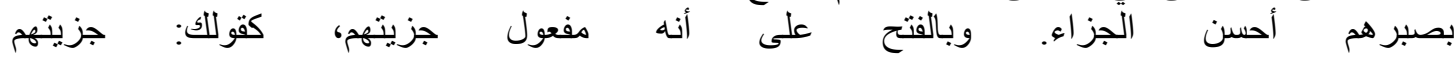

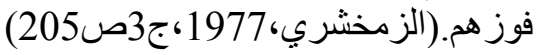

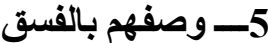

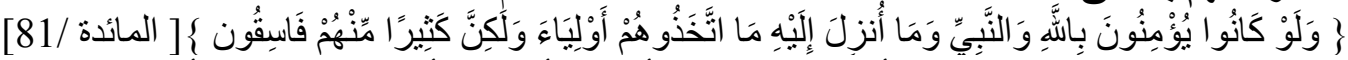

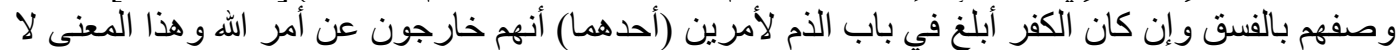

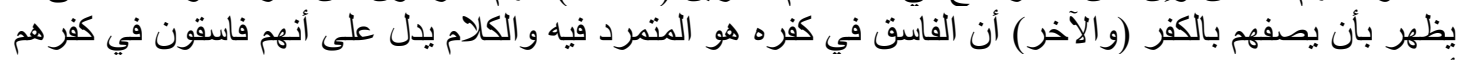

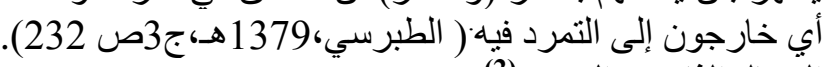

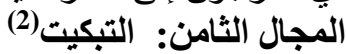

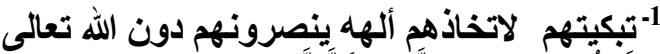

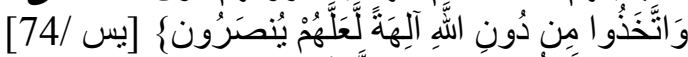

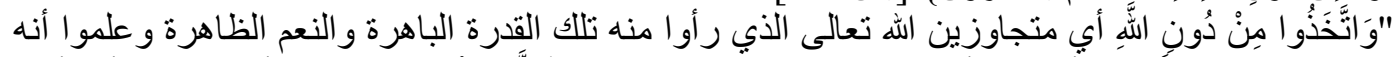

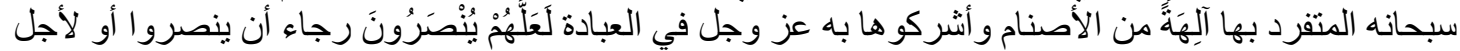

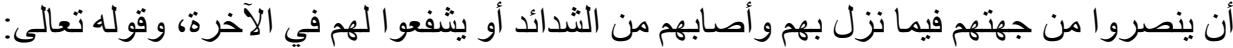

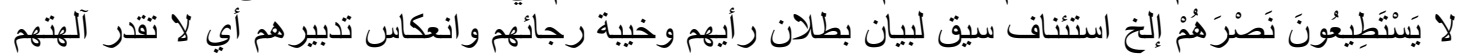

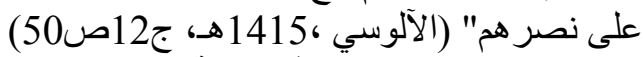

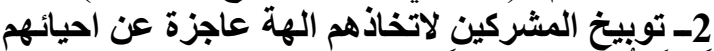

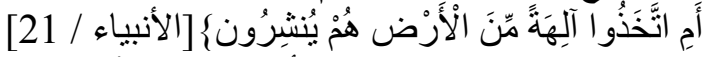

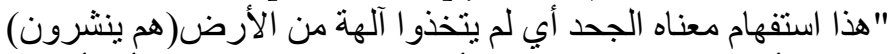

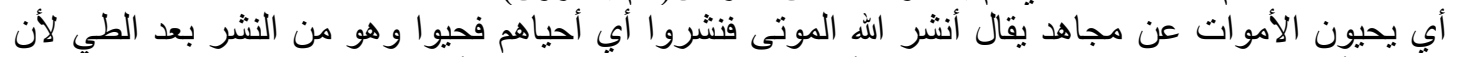

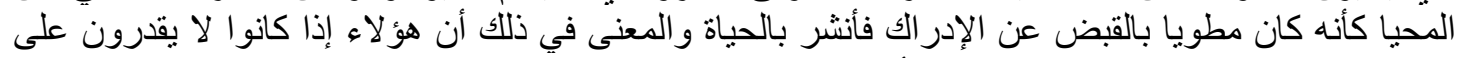

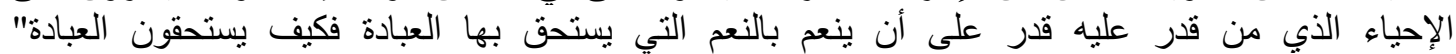

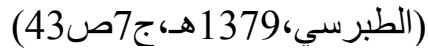

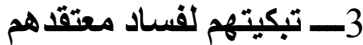

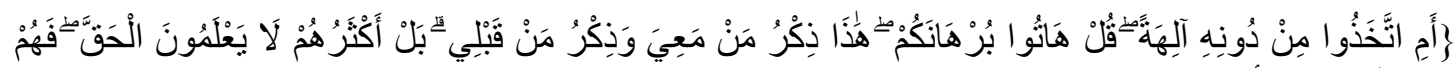

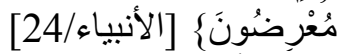

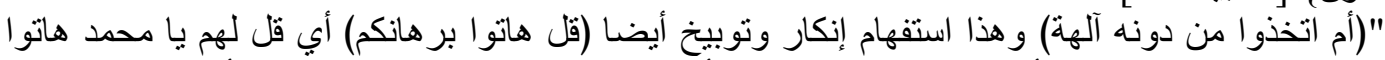

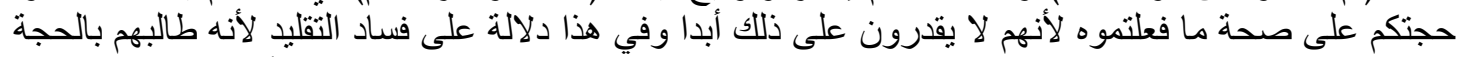

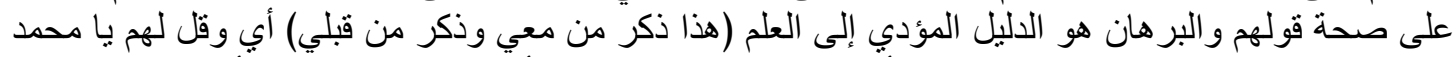

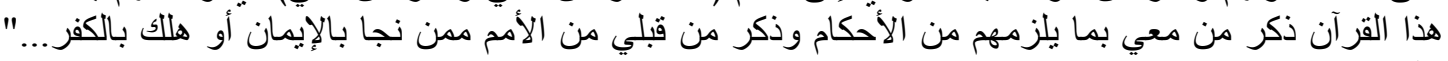

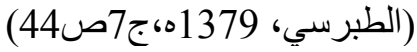
4- 4- تبكيتهم لاختيار هم الخاطئ

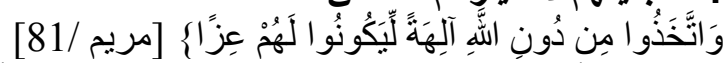

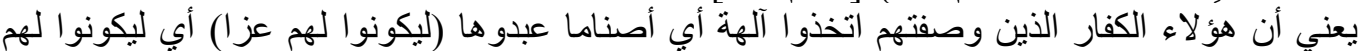

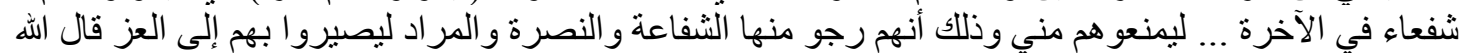

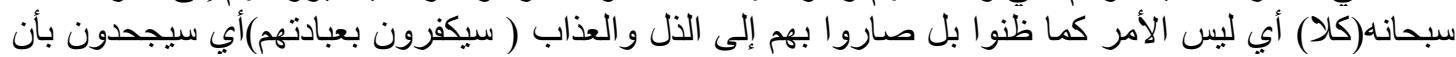

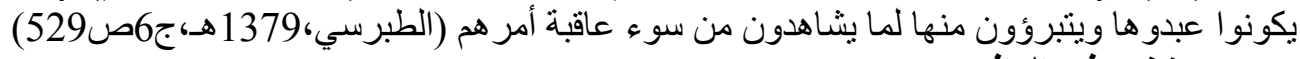

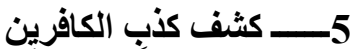

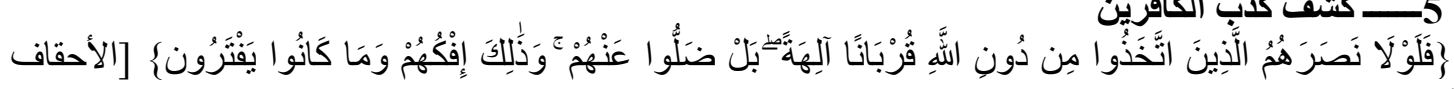

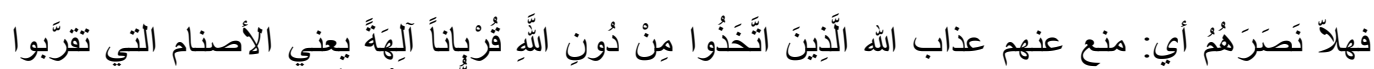
$[28 /$

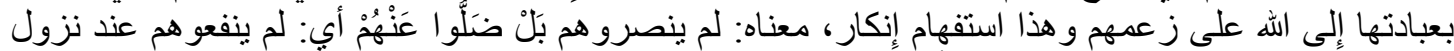

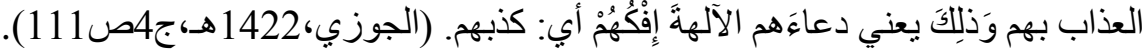




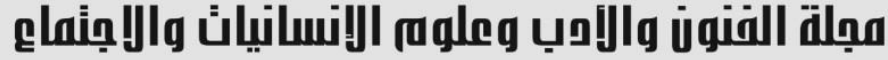

Journal of Arts, Literature, Humanities and Social Sciences www.jalhss.com

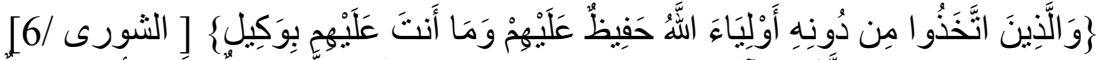

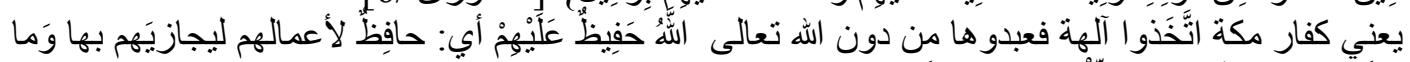

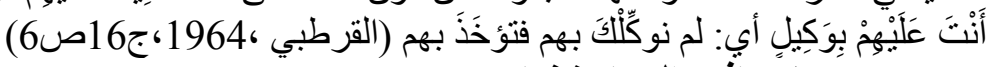

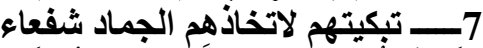

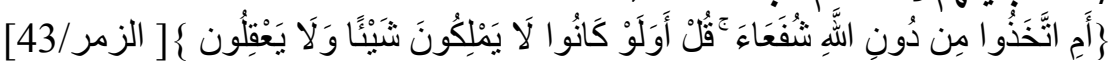

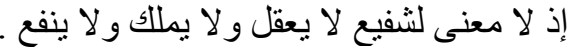

8ـ تبكيتهم لأن حقت عليهم الضلالة لألة

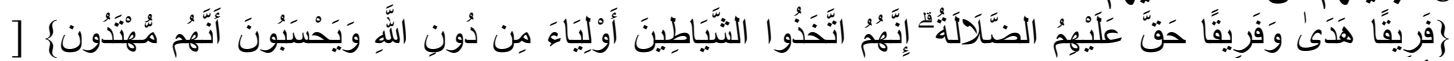
[الأعراف /

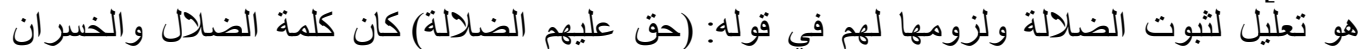

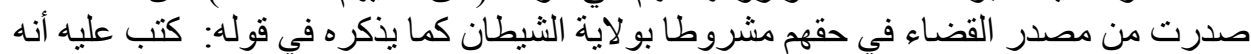
فلما تولوا الثياطين في الدنبا حقت عليهم الضلالة ولزمتهم لزية لزوما لا انفكالك بعده أبدا ـالطباطبائي (19201429،

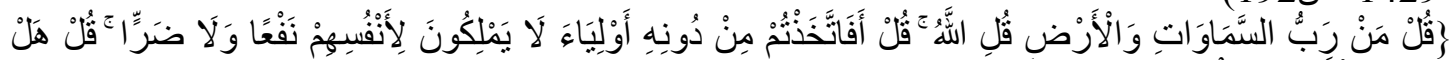

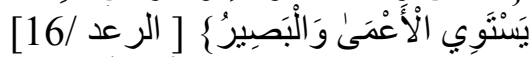

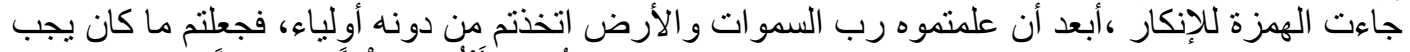

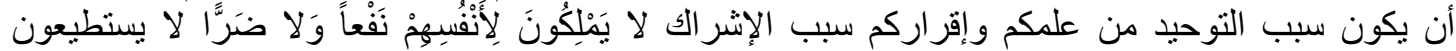

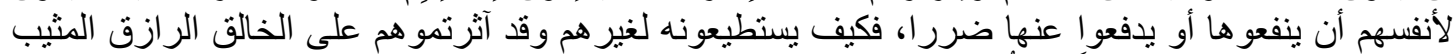

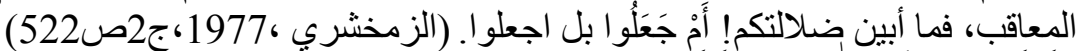

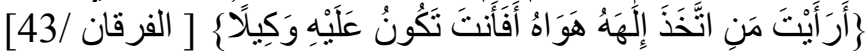

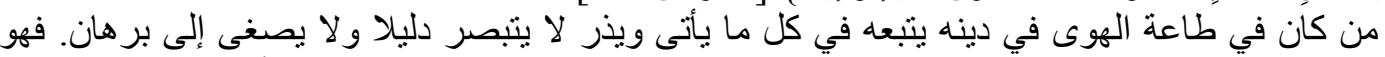

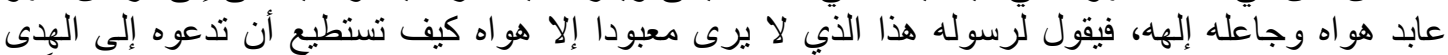

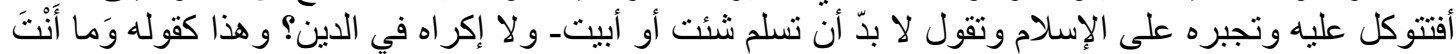

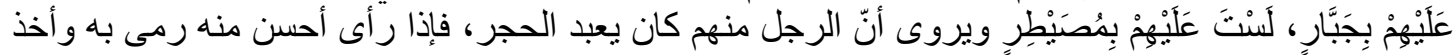

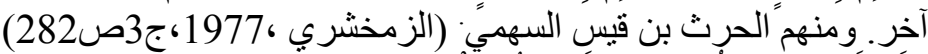

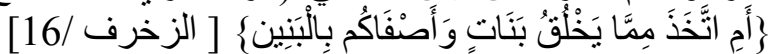

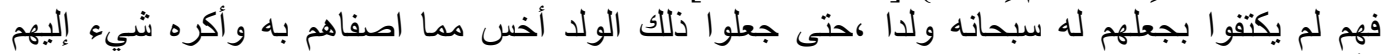

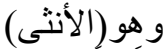

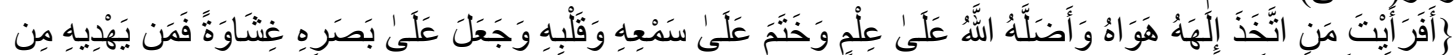

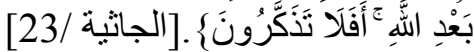

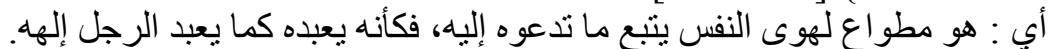

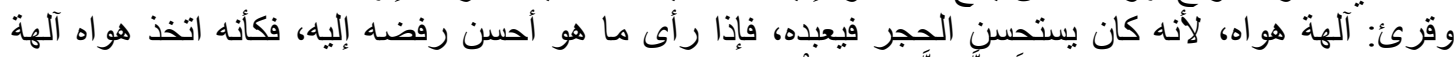

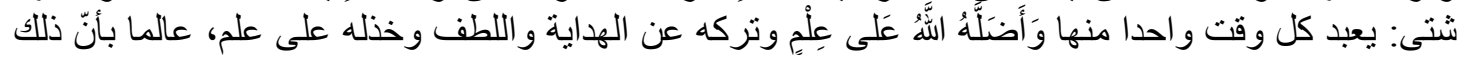

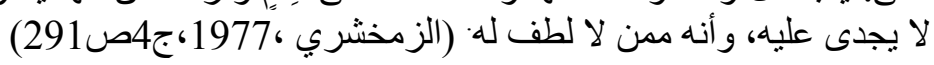

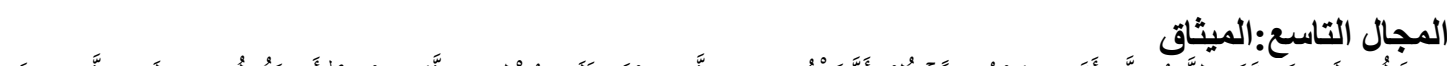

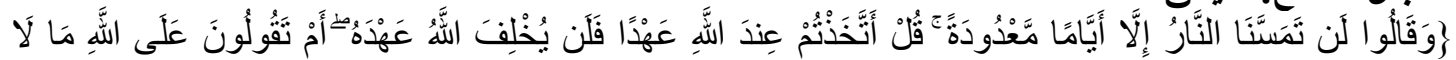

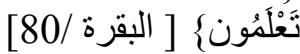




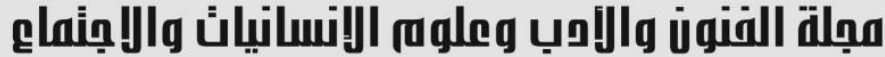

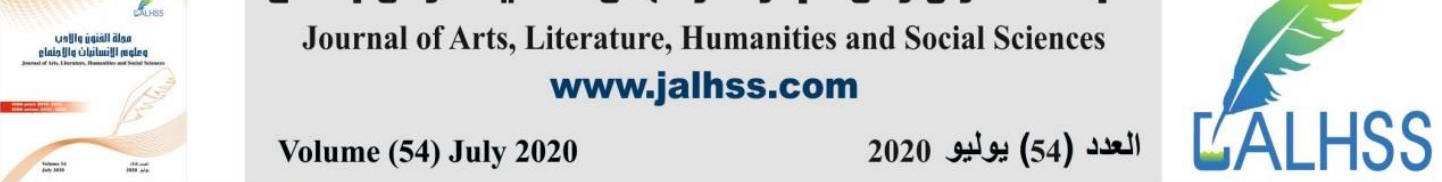

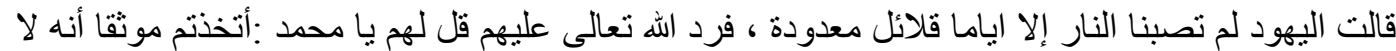

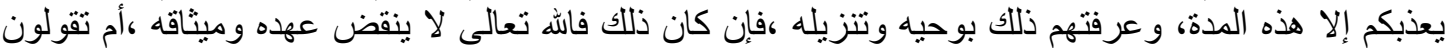

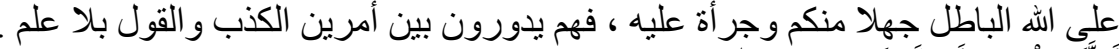

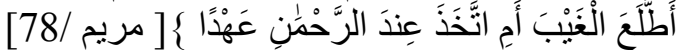

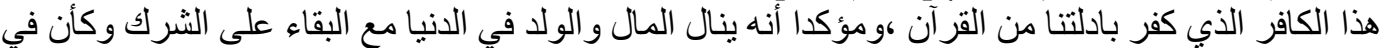

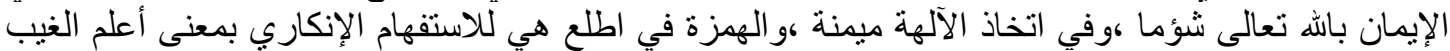

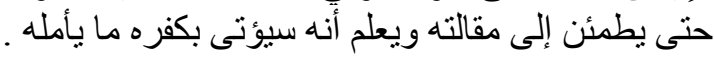
المجال العاشر : الإنذار

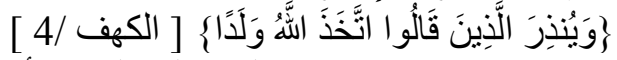

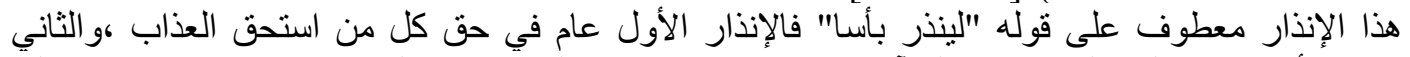

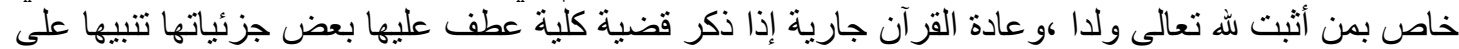
كونه أعظم جزئيات ذلك الكلي، و وهنا العطف يؤكد أن أقبح أنواع الكفر و المعصية إثبات الولد الله تعالى ـ (الرازي

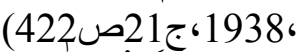

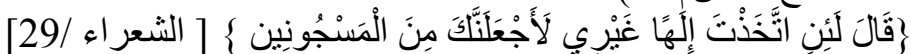

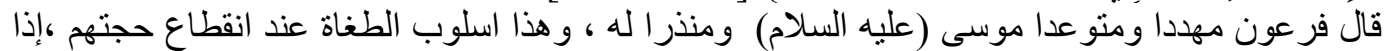

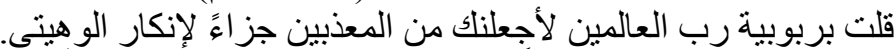

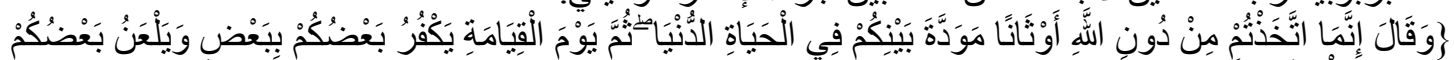

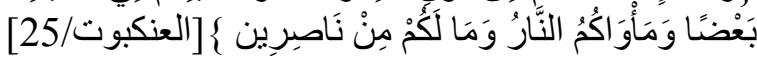

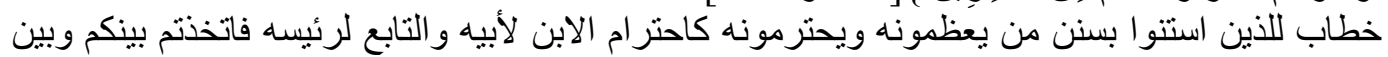

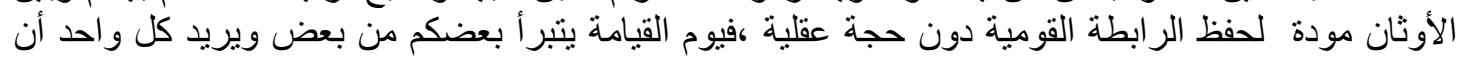

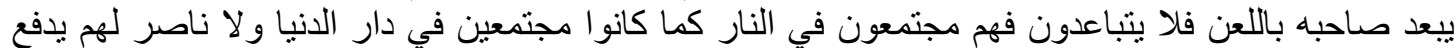

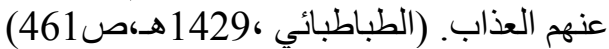

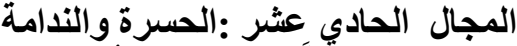

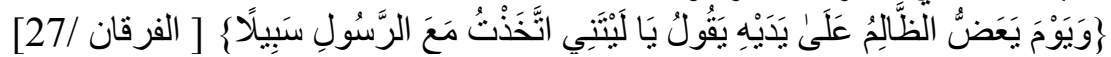

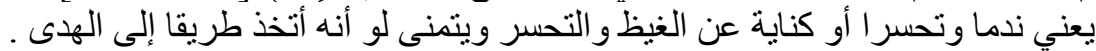

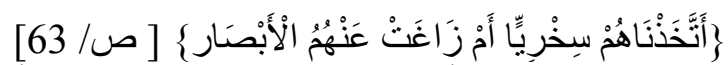

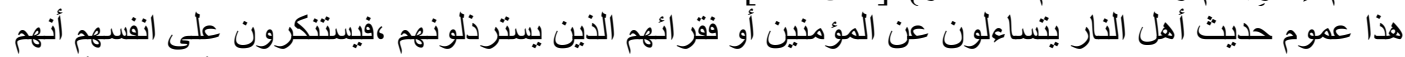

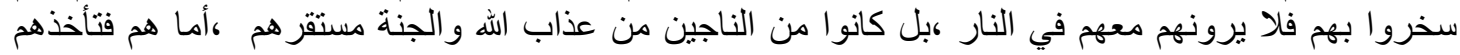

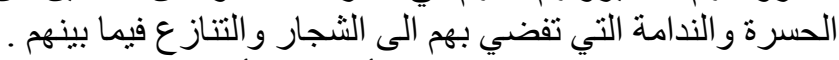

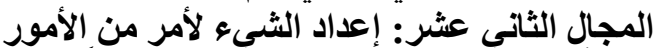

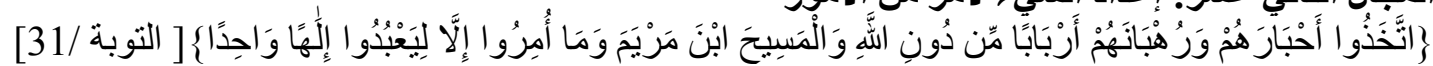

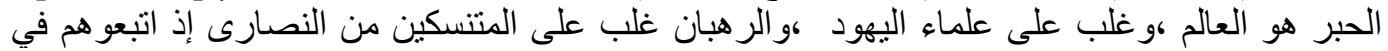

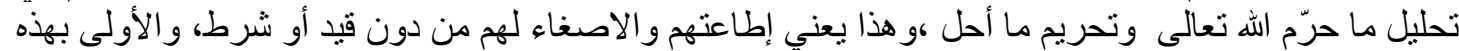

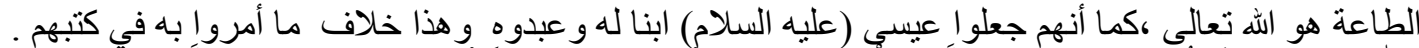

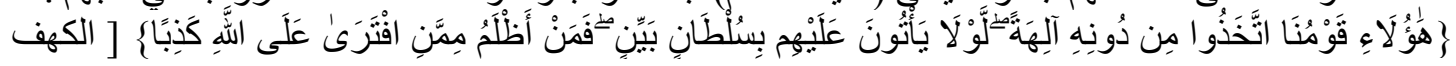

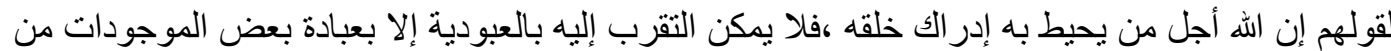

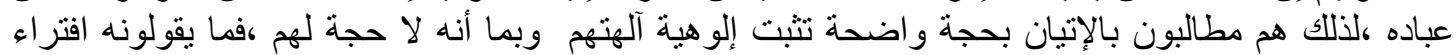

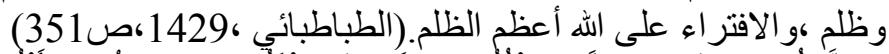

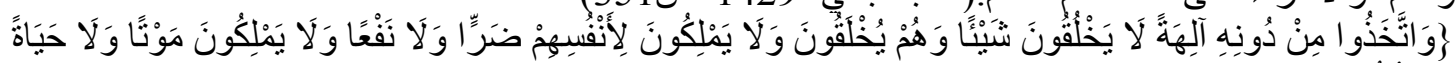

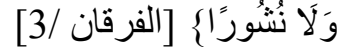

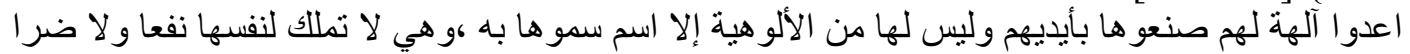

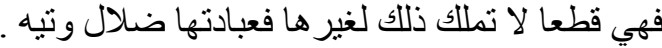




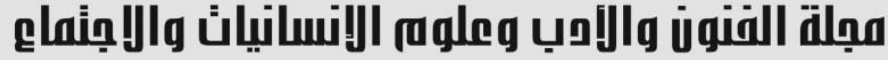

\section{Journal of Arts, Literature, Humanities and Social Sciences www.jalhss.com

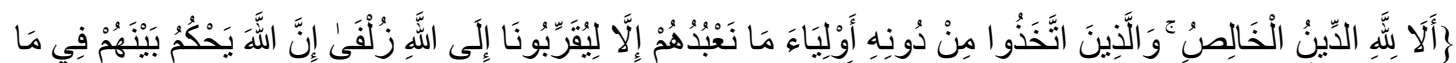

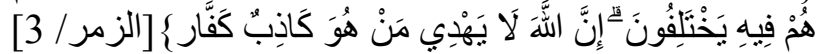

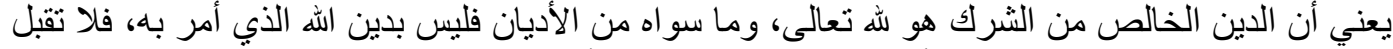

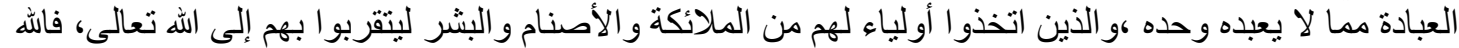

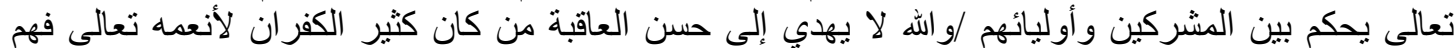

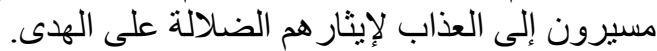

\section{المجالات الالآلية لصيغة (تتخذ ويتخذ)في الزمن المضارع الدالة على البر والإحسان}

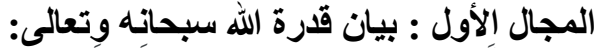

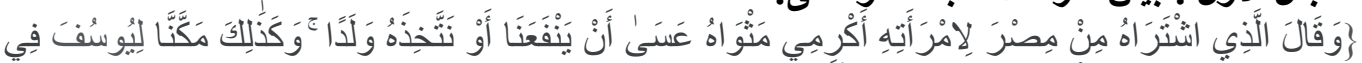

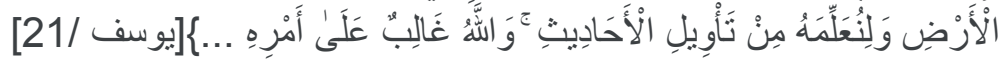

تجلت قدرة الله تعالى في أن يكون يوسف (عليه السلام) ذلك العبد العبراني الذي بيع في سوق النخاسة

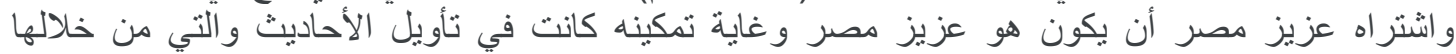

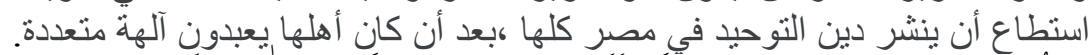

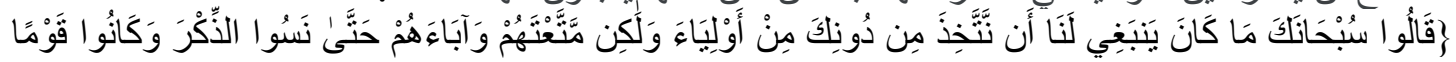

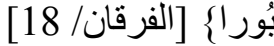

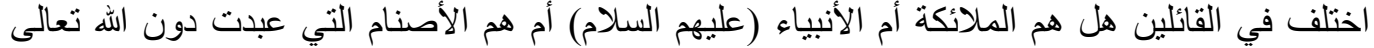

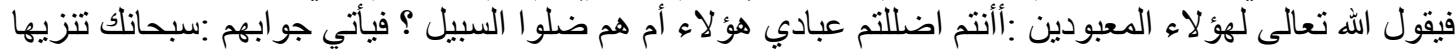
للك عن الثريك و عن ان يكون لنا معبود سو الك ،فليس لنا أن نو اللي أعداءك بل بل أنت ولينا من دونهم .

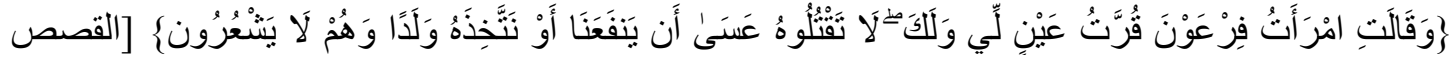

شفعت السيدة آسيا زوج فرعون لموسى (عليه السلام ) عندما جاؤوا به من اليم لأن الله تعالى ألقى في قلبها

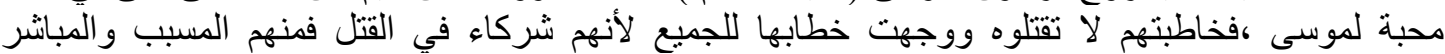

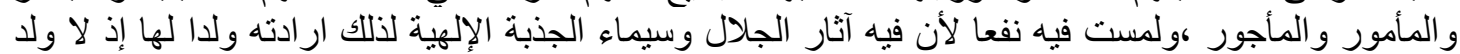

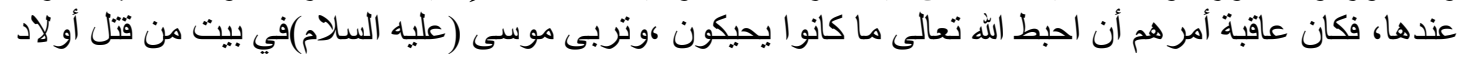

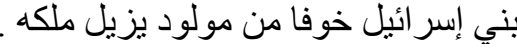

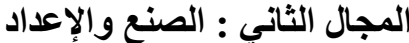

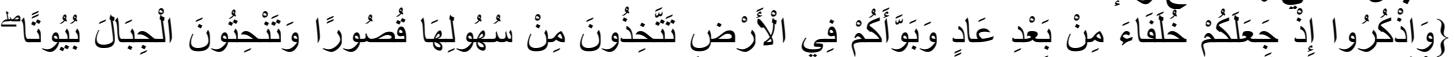

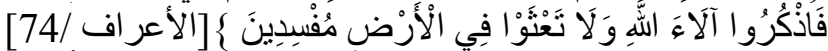

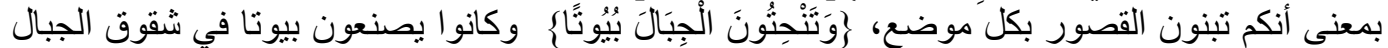

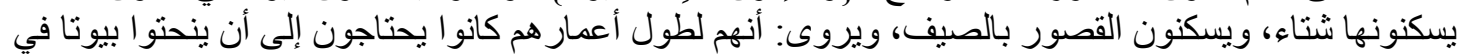

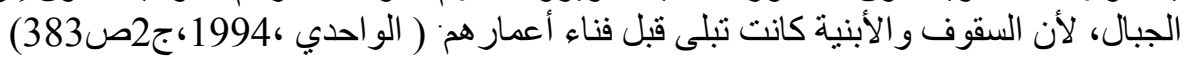

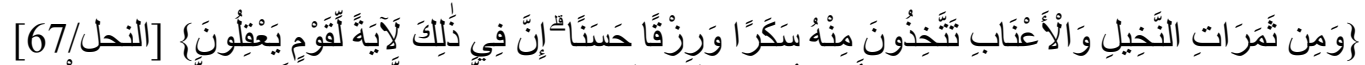

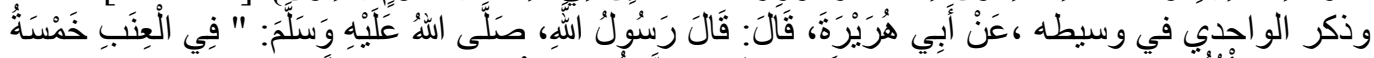

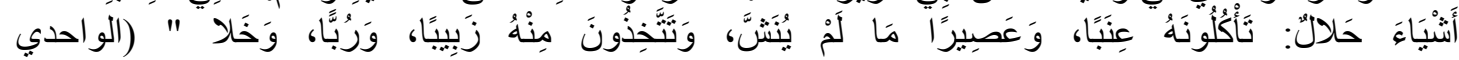

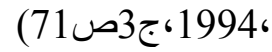

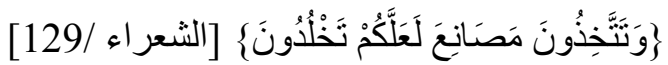




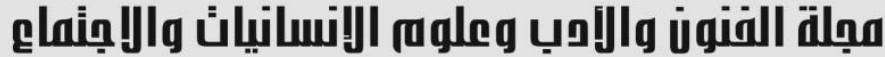

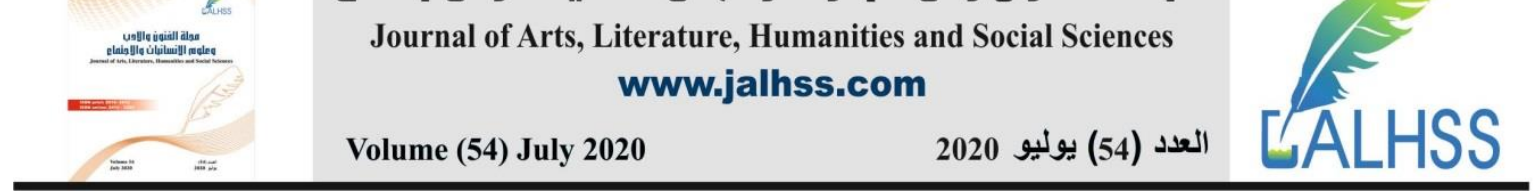

المصانع التي يتخذها الناس من الأبنية و الآبار ، قال أبو عبيدة: كل قباء مصنعة. قال ابن عباس: هي الأبنية.

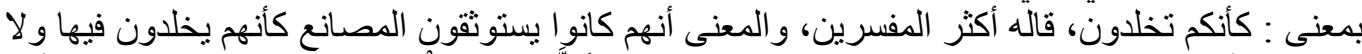

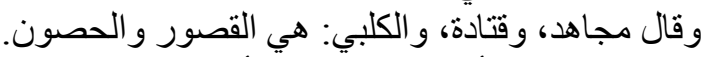

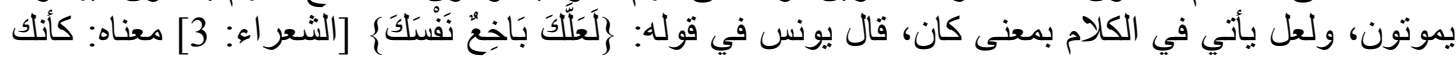

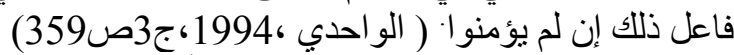

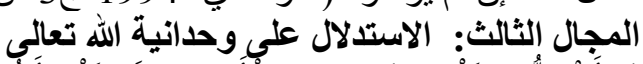

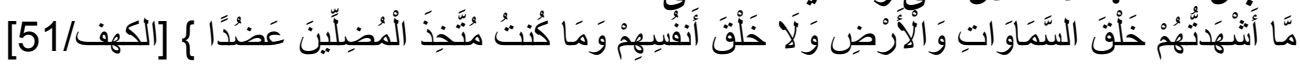

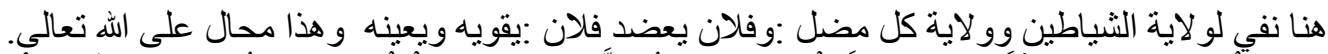

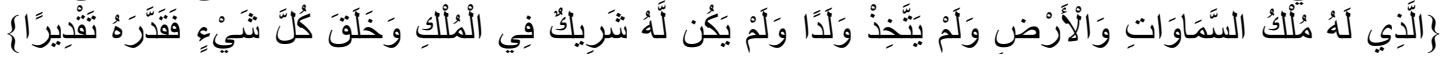
[الفرقان/2]

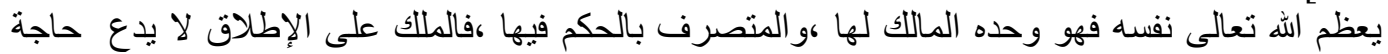

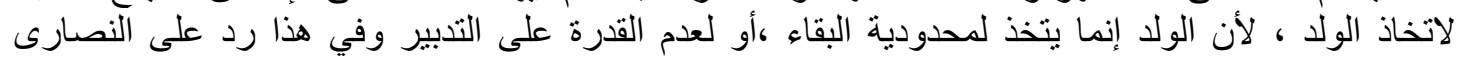

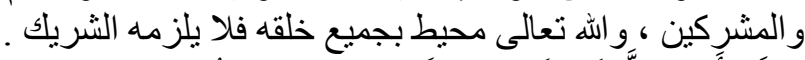

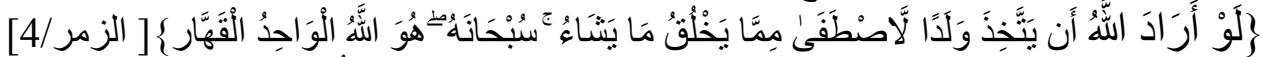

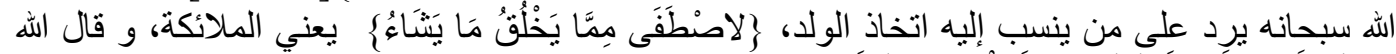

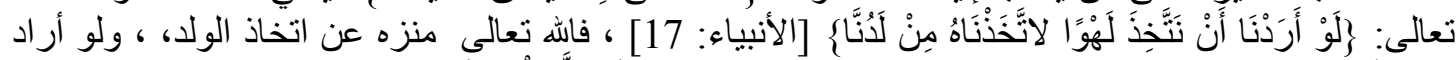

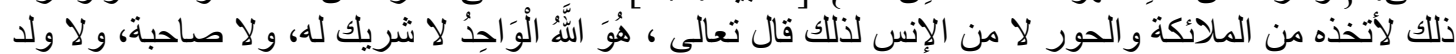
القهار لخلقه، قهر ما خلق بالموت والحور لالفناء و هو حي لإنس لأيموت.

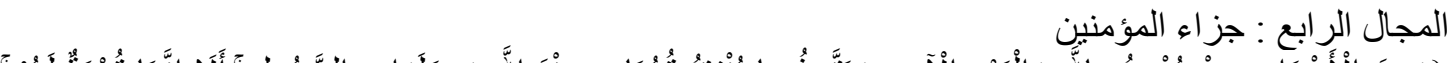

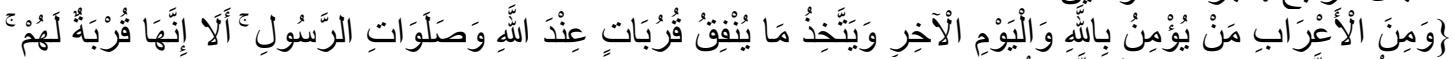

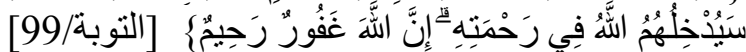

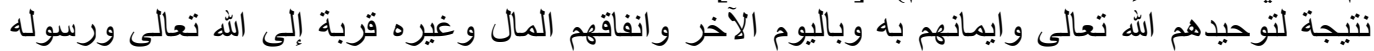

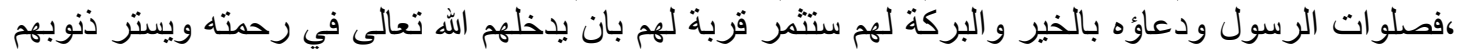

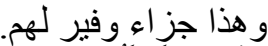

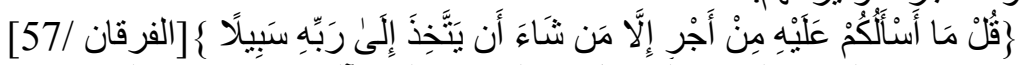

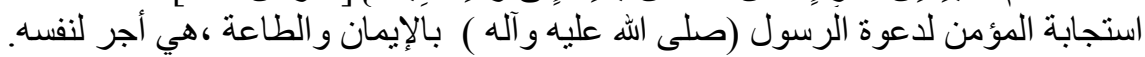

المجال الخامس: الإنكار

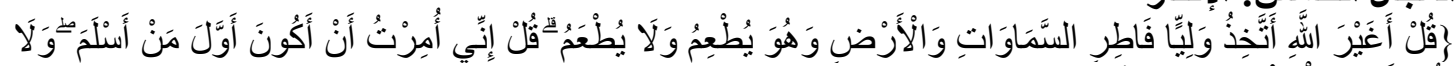

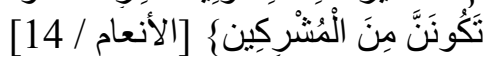

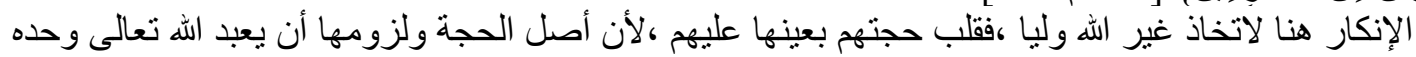
مع نفي كل شريك عنه ،لأنه سبحانه مصدر كل النعم ،و عبادته شكر يزيد الأن النعم ويدفع النقم.

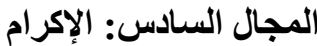

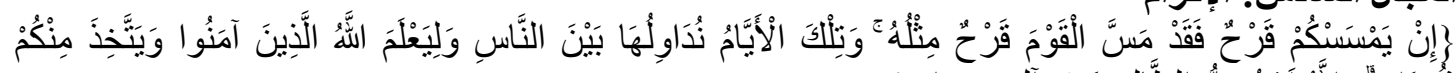

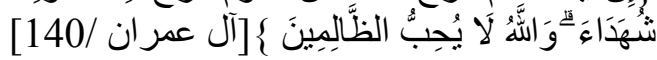
بمعنى : يكرم بعضكم بالثهادة.

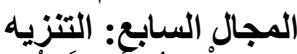

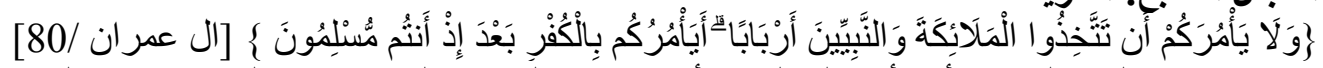

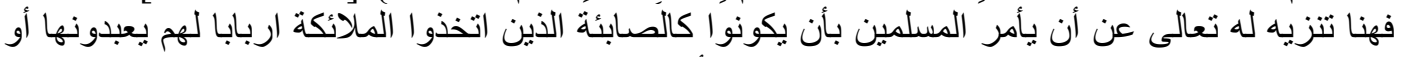

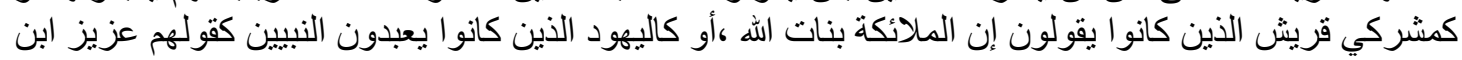




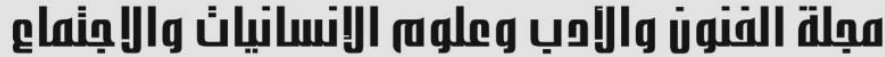

Journal of Arts, Literature, Humanities and Social Sciences www.jalhss.com

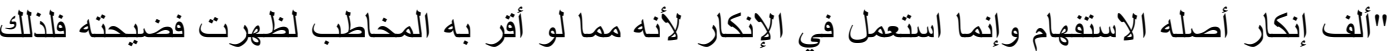

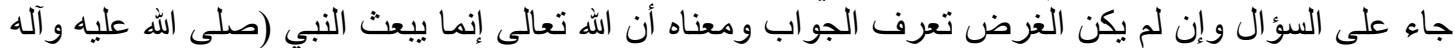

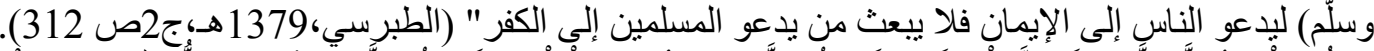

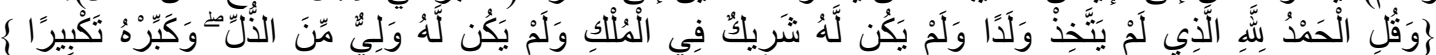

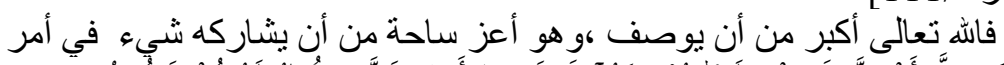

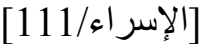

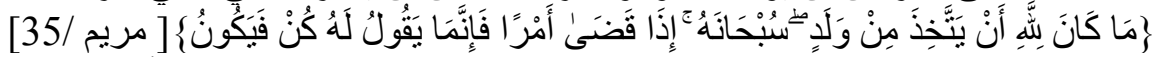

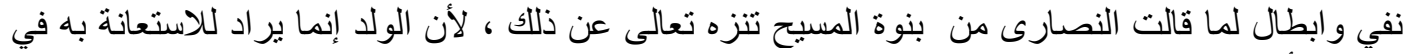

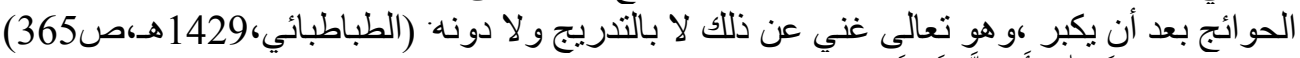
年

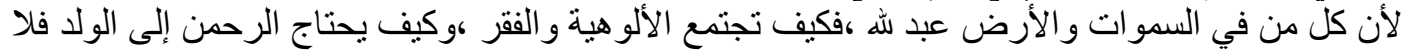

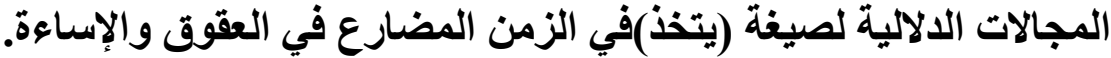

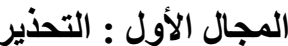

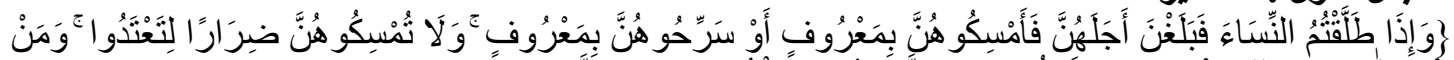

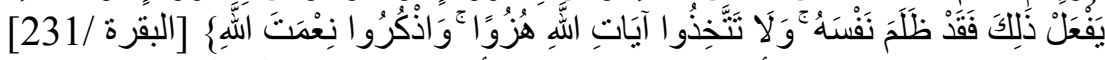

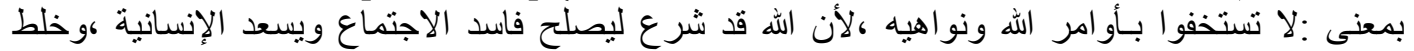

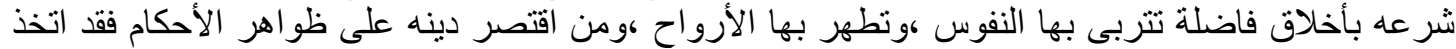

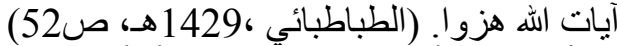

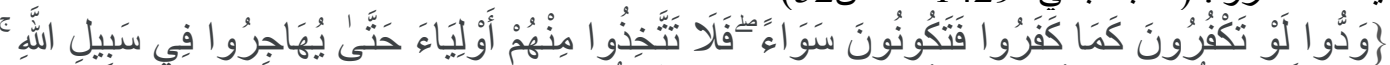

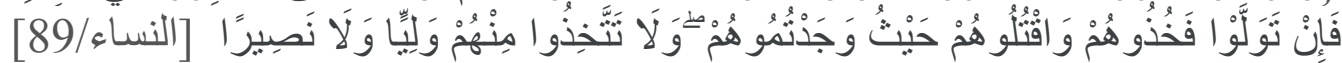
هذا تحذير للمؤمنين ونهي لهم عن اتخاذ الكافرين اولياء ـفعلى المؤمنين أن يكلفو هم المهاجرة

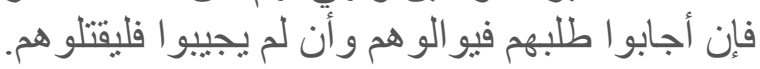

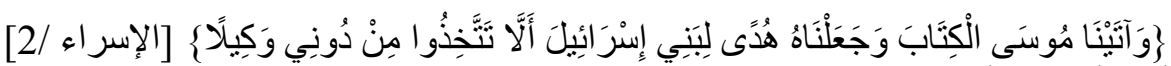

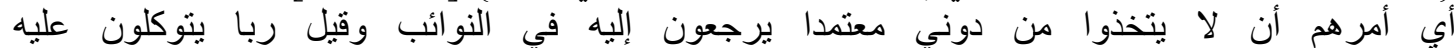

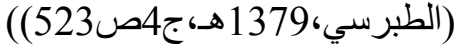

المجال الثاني : جزاء الكافرين

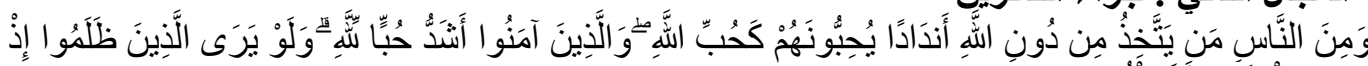

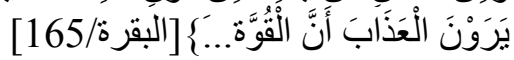

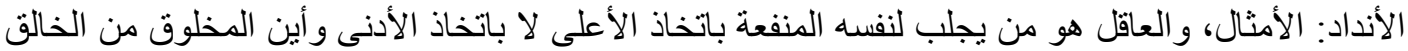

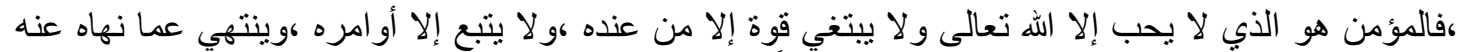

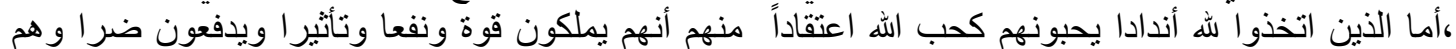

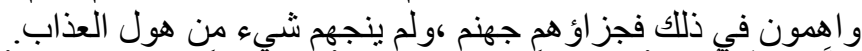

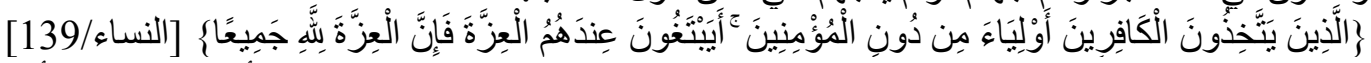

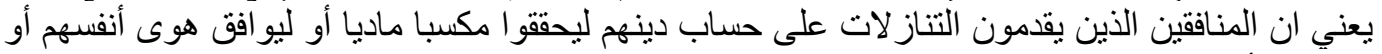

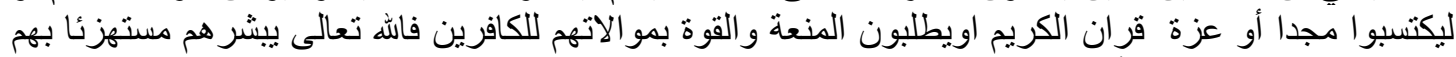

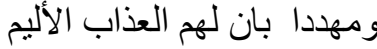

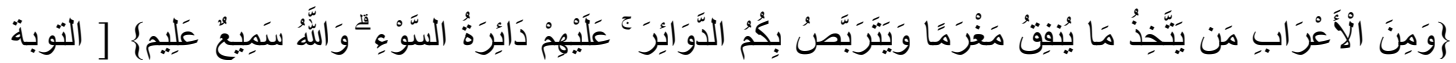




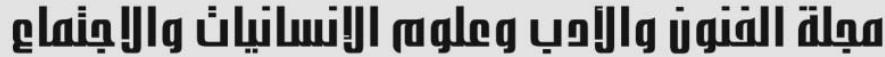

Journal of Arts, Literature, Humanities and Social Sciences www.jalhss.com

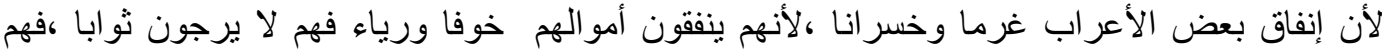

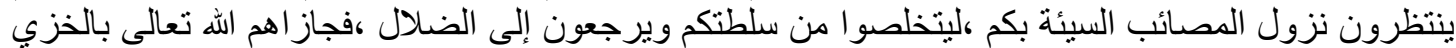

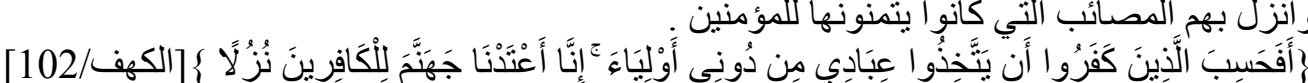

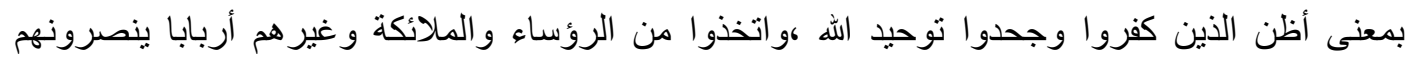

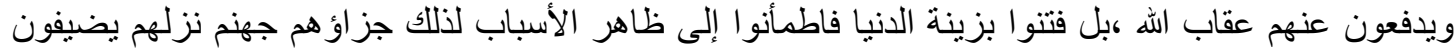
فيها ويصلون نار ها.

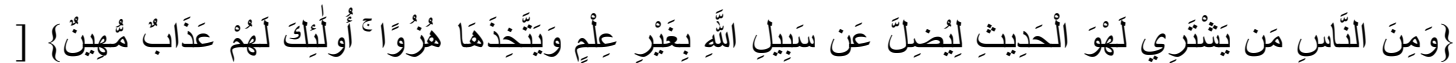
]6/ لقمان

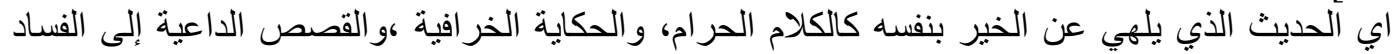

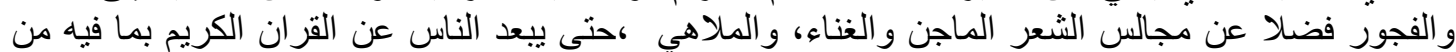

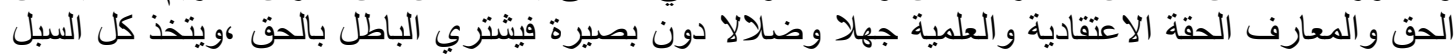

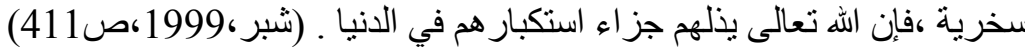

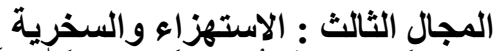

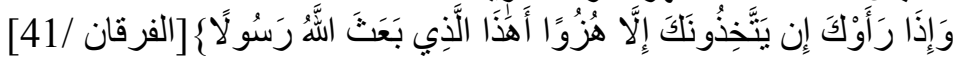

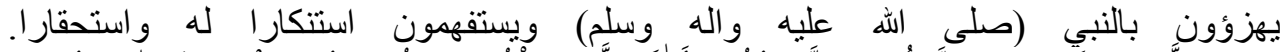

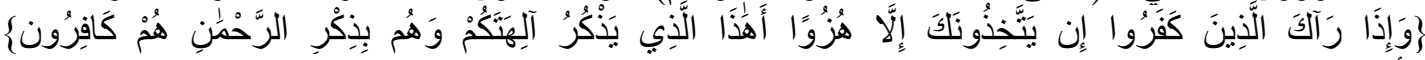

[الأنبياء/36

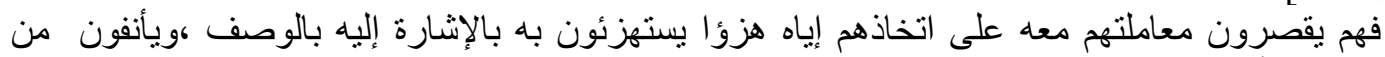

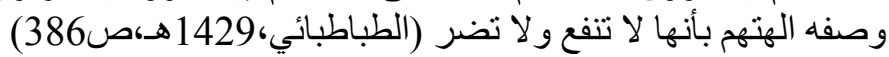

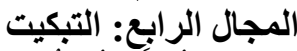

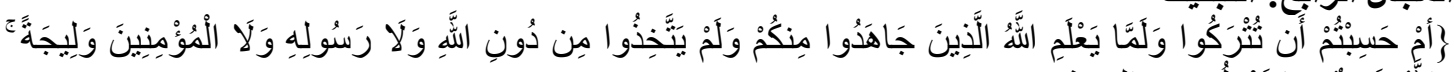

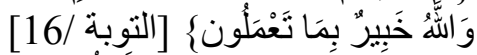

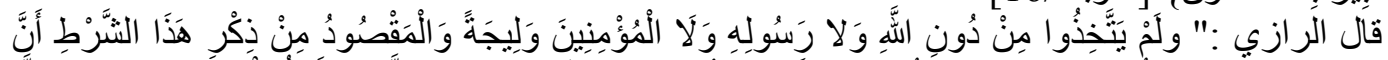

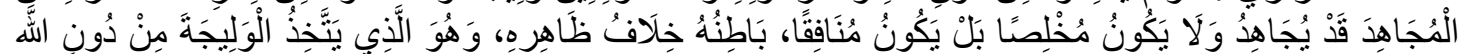

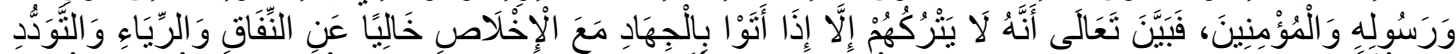

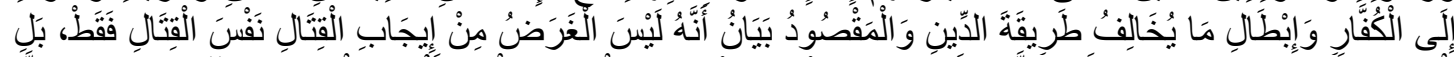

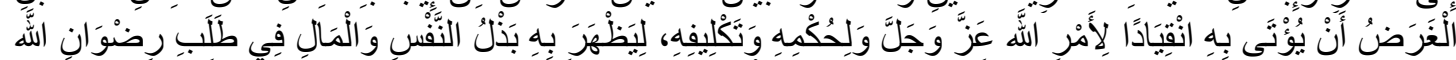

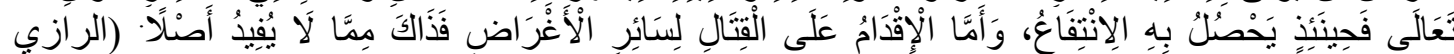

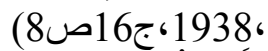

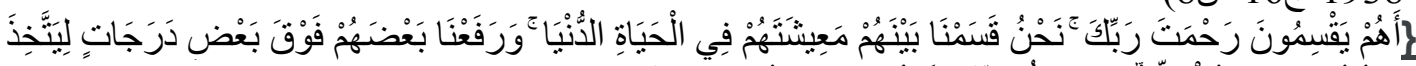

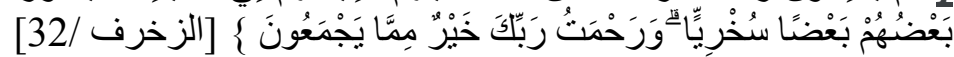

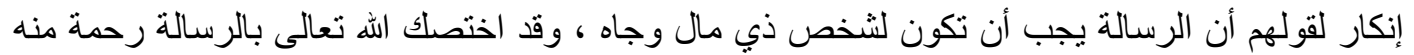

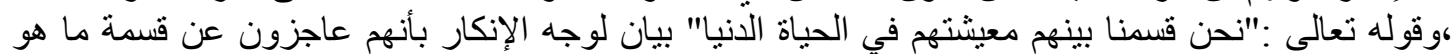

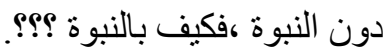

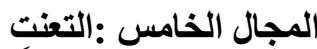

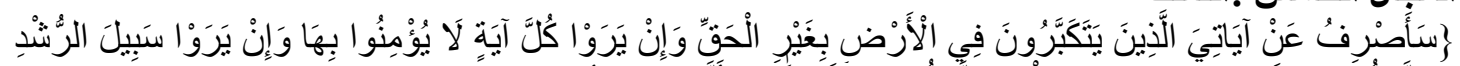

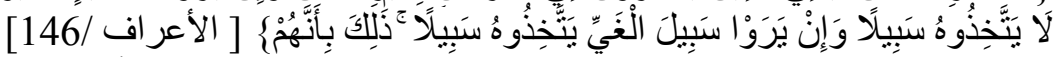

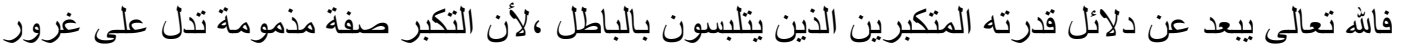

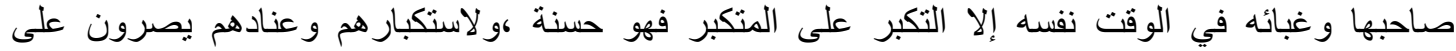




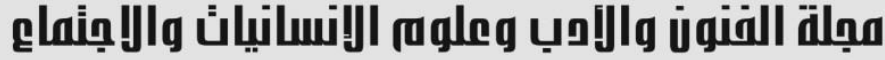

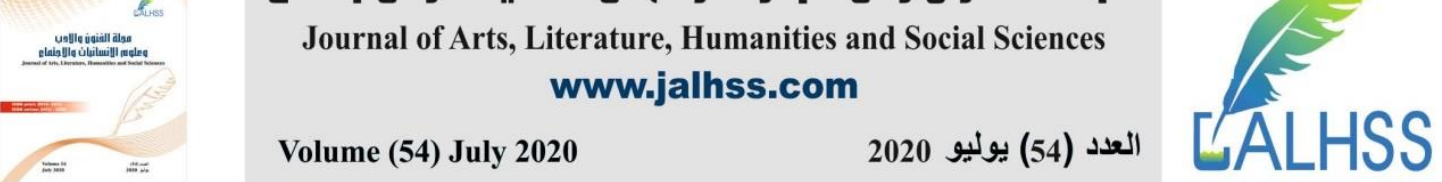

الانحر اف عن طريق الرشد وهم يعرفونه رشدا ،فلا يعذرون بخطأ ولا جهل و لا اشتباه ،ويسلكون طريق الغي

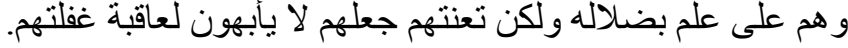

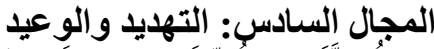

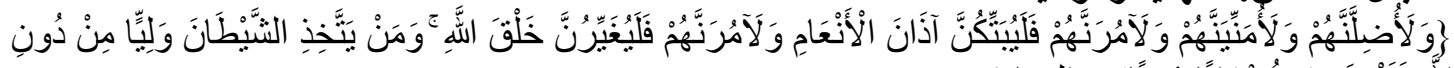

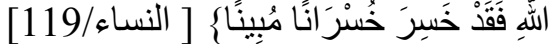

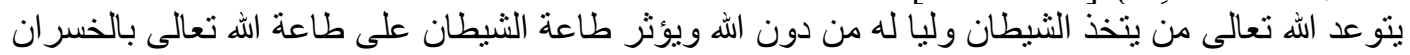

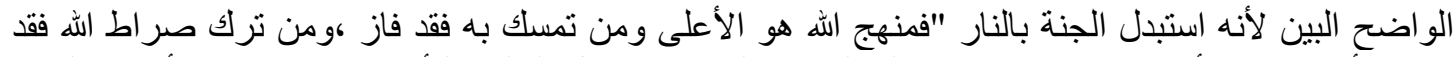

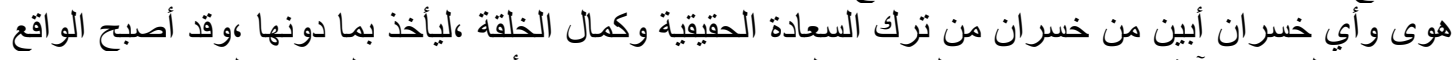

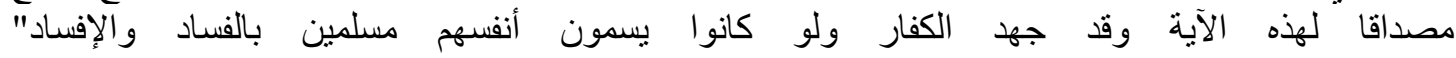
(الطباطبائي،1429هـ، ل1220)

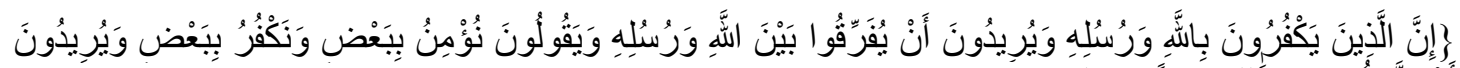

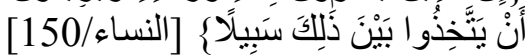

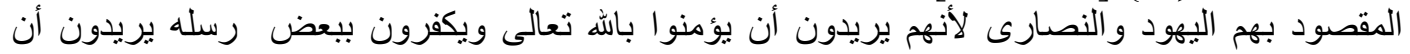

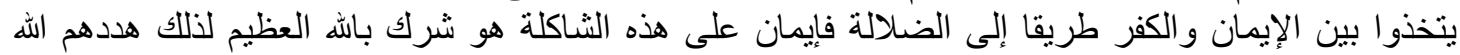

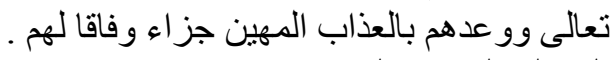

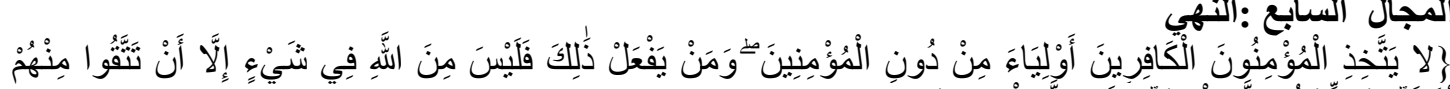

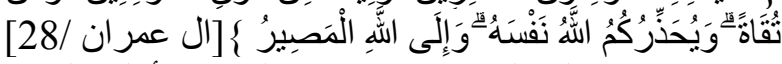

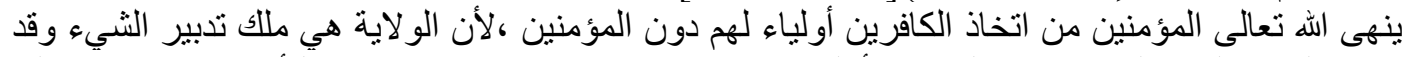

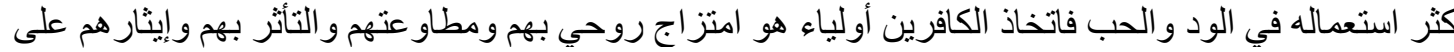

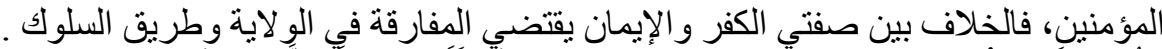

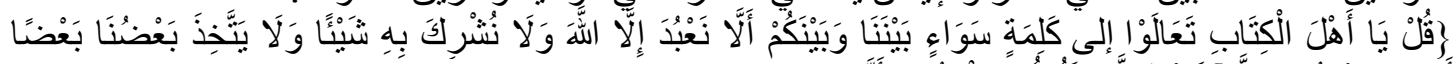

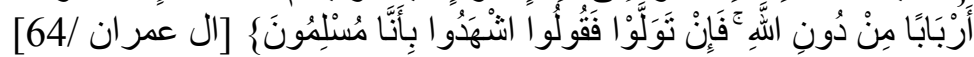

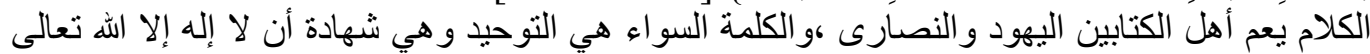

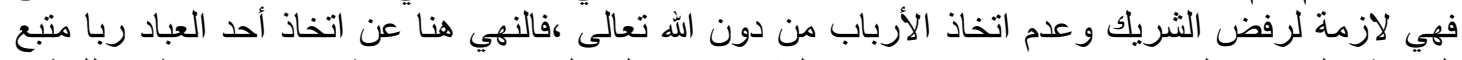

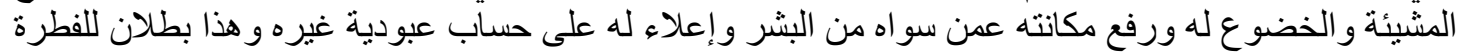

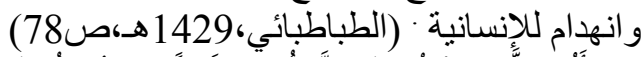

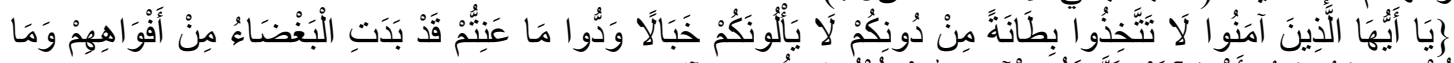

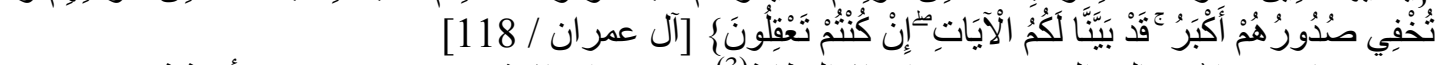

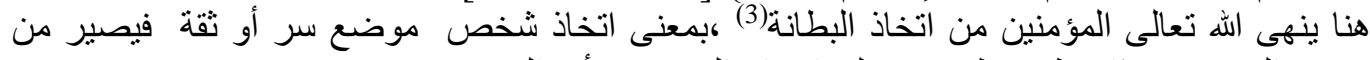

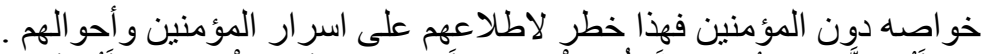

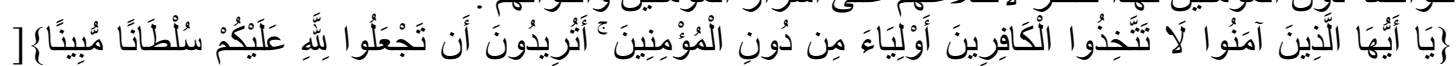

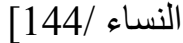

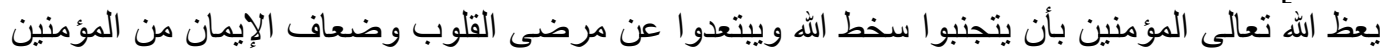

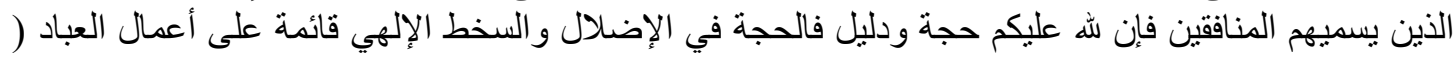

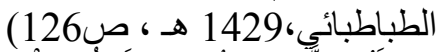

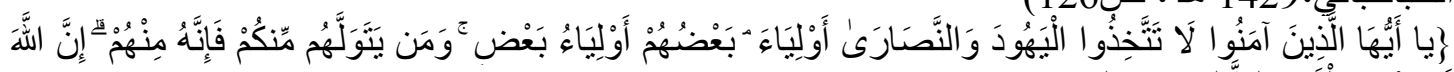

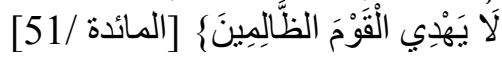

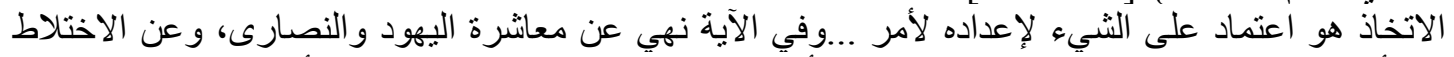

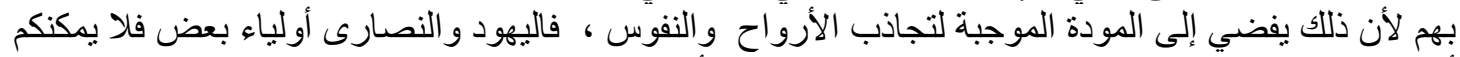

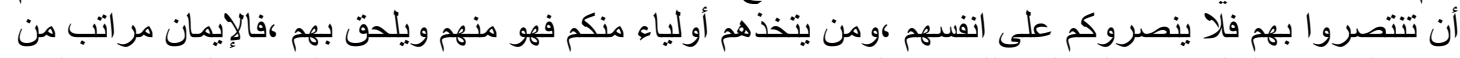

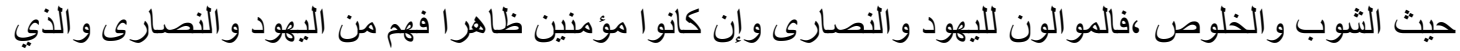

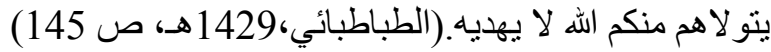




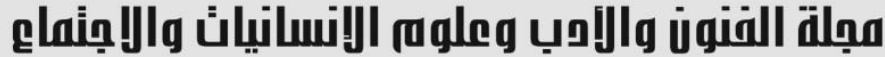

]

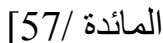

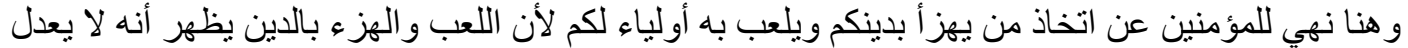

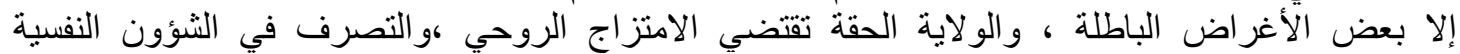

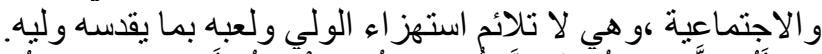

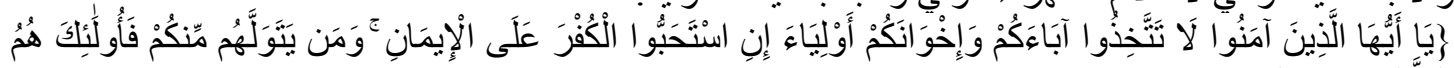

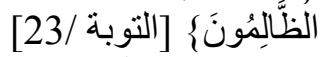

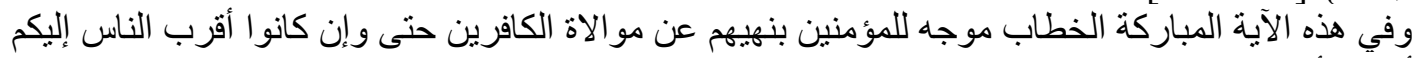

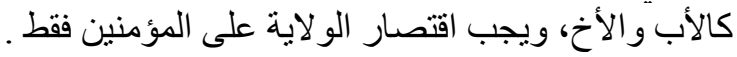

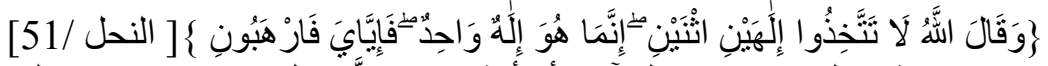

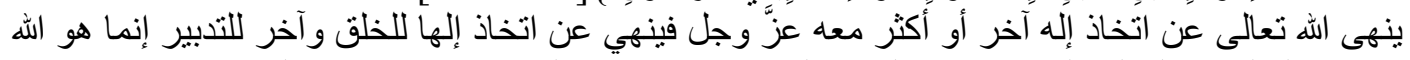

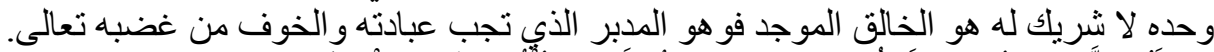

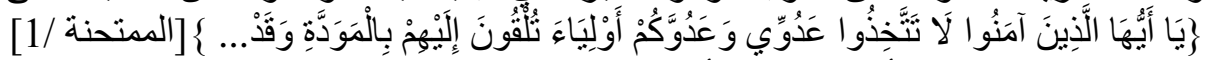

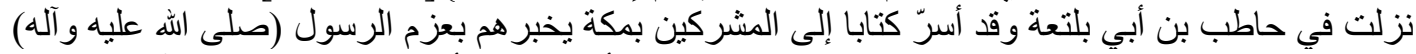

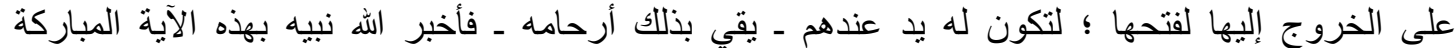
(الطباطبائي ،1429هـ ، كـ111)

المجال الثامن :الإنكار

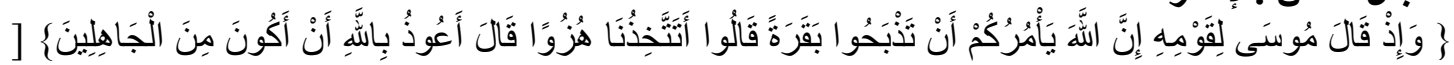

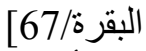

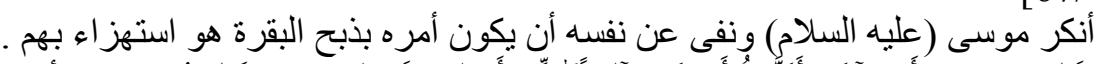

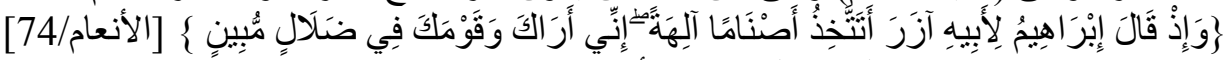

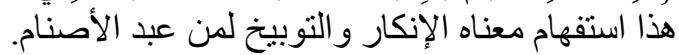

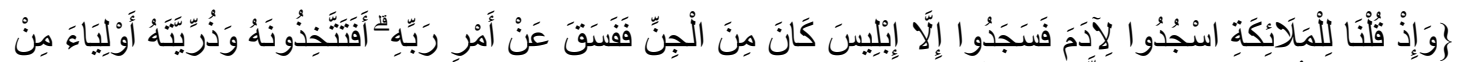

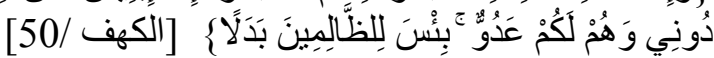

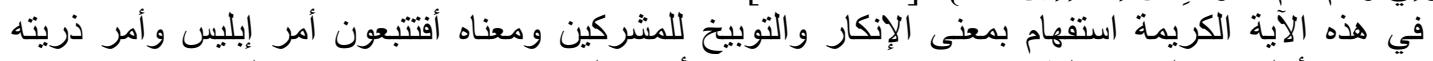

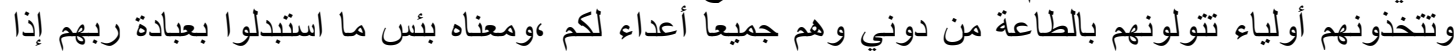

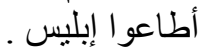

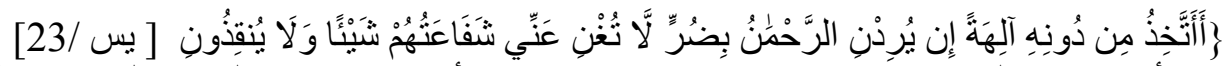

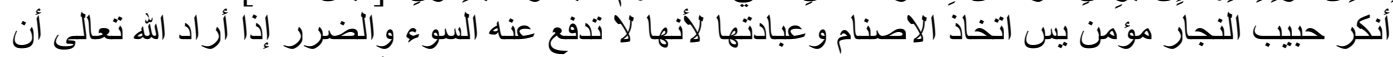

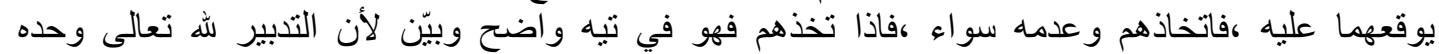

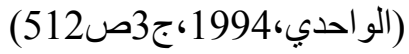

أن

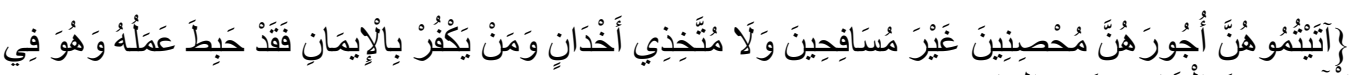

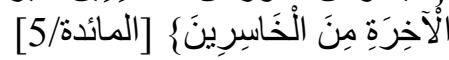




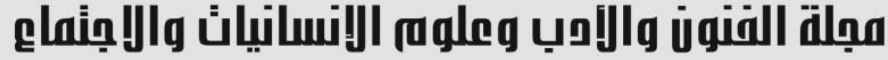

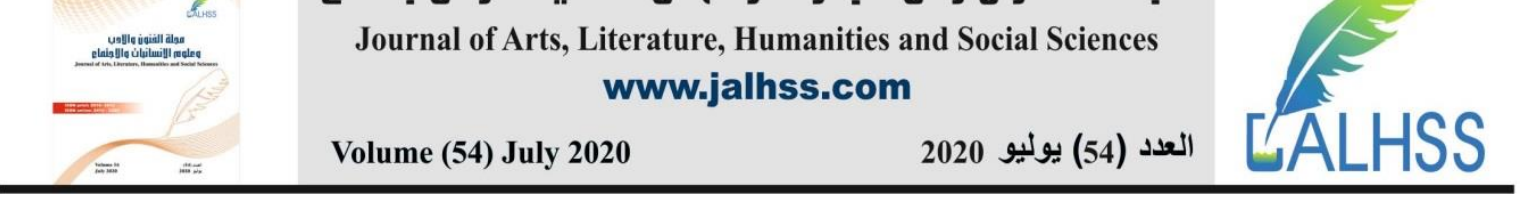

وفي الآيتين الكريمتين نهي عن اتخاذ الخليلة ،للزنا بها سرا ،و الخدن الحبيب و الصاحب تقال للذكر

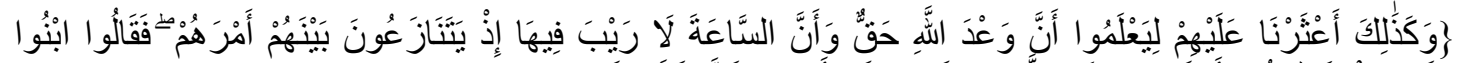

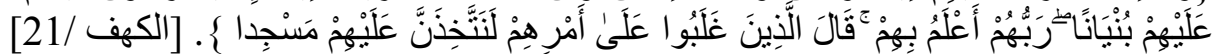

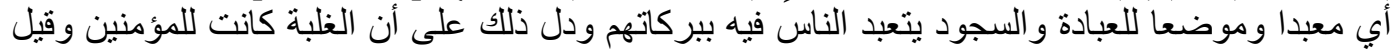

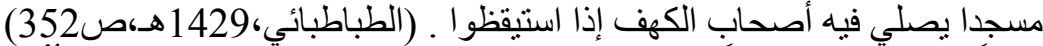

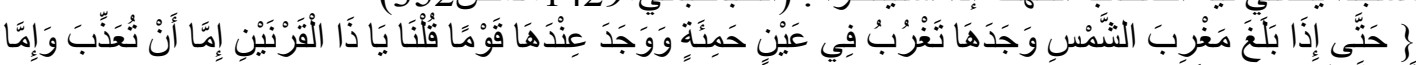

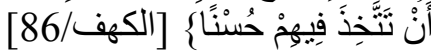

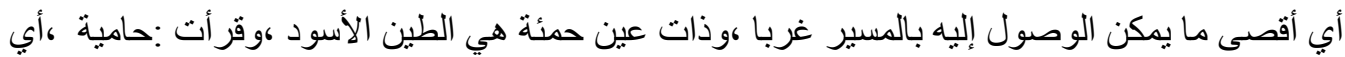

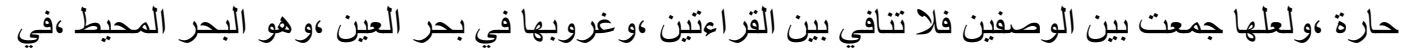

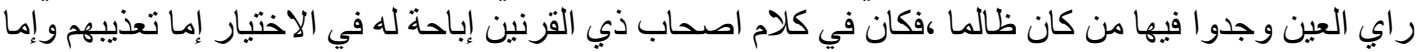

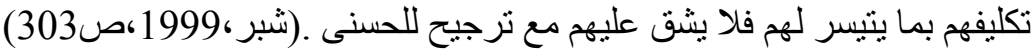

المجال المجال العاشر: التدامة والحسرة

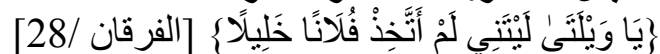

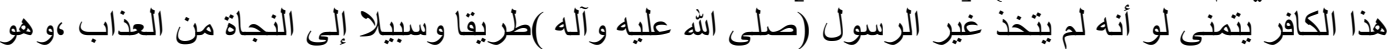

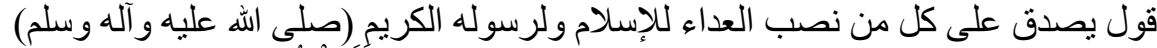

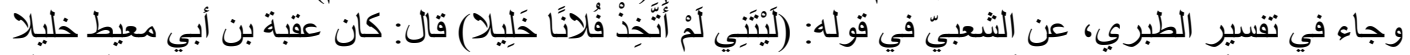

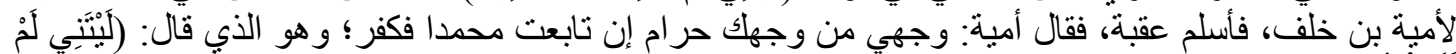

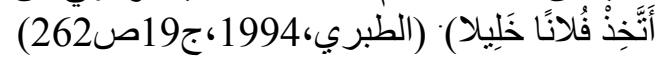

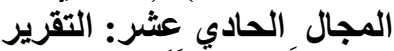

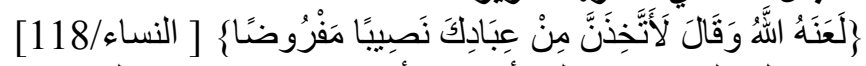

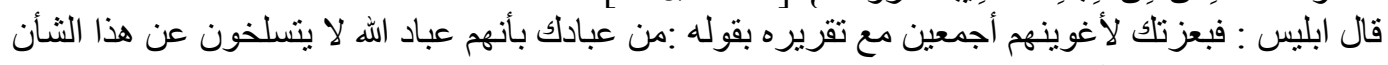

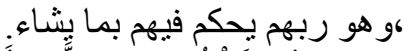

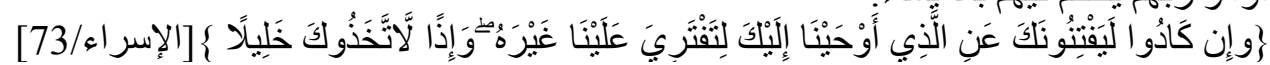

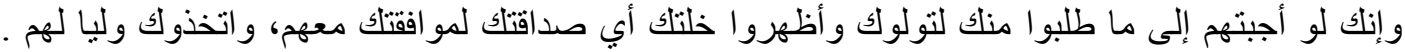

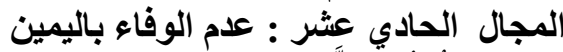

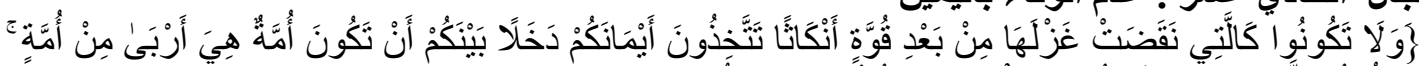

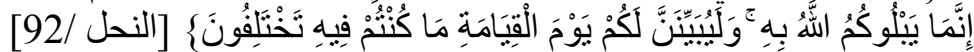

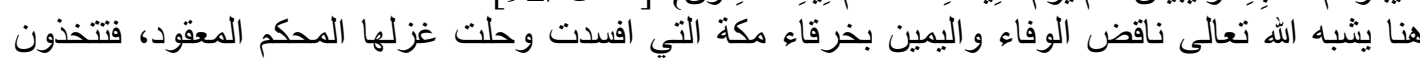

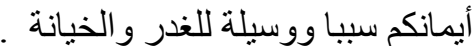

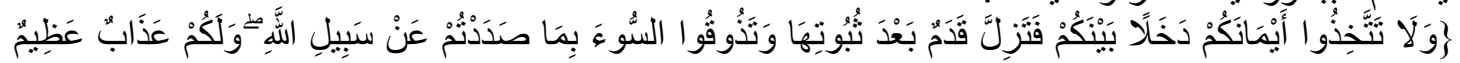
[94/النحل هنا نهي استقلالي عن الخدعة باليمين ،فزلة القدم بعد ثبوتها مثل لنقض اليمين بعد توكيده. 


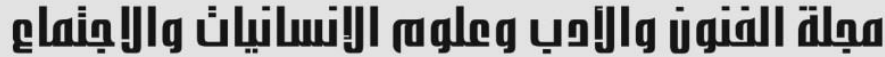

Journal of Arts, Literature, Humanities and Social Sciences
www.jalhss.com

أولا :المجالات الدالة على البر و الإحسان

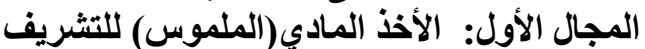

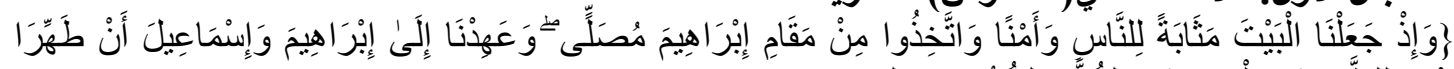

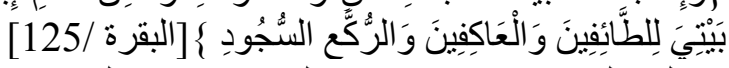

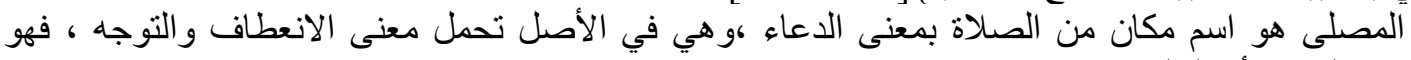

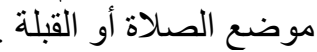

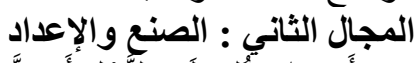

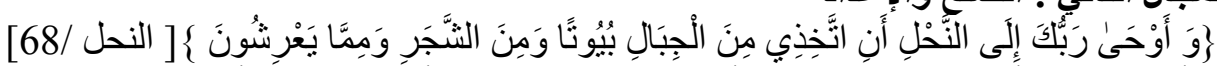

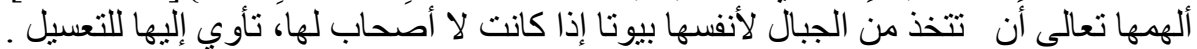

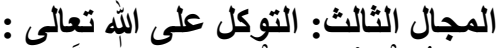

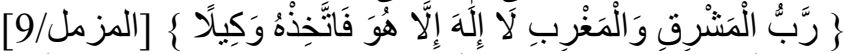

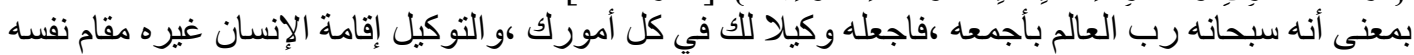

\section{تانياً: المجالات الدالة على العقوق والإساءة}

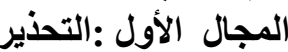

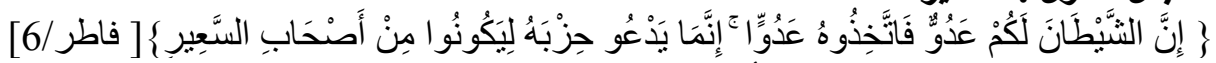

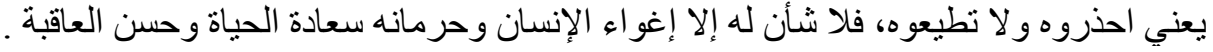

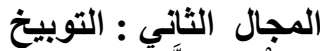

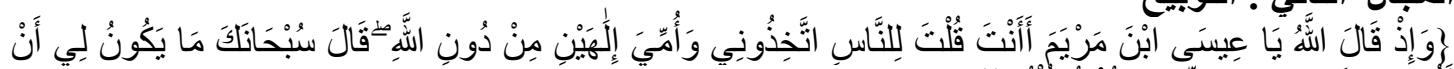

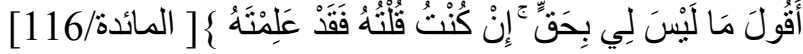

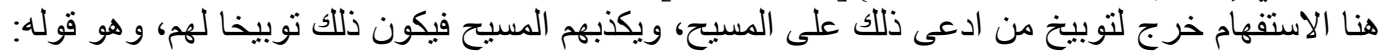

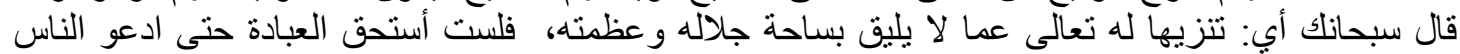

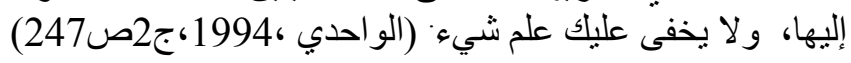

الخاتمة

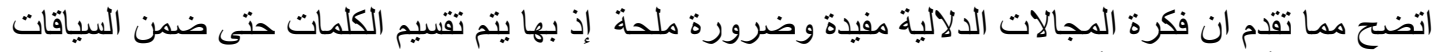

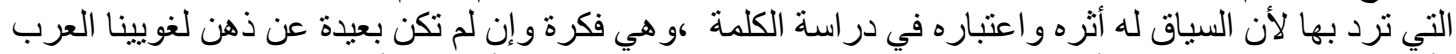

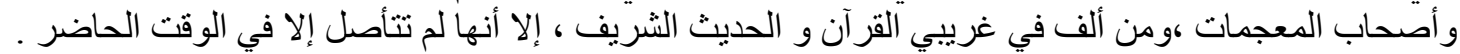

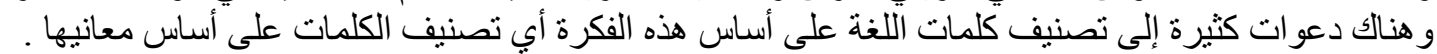

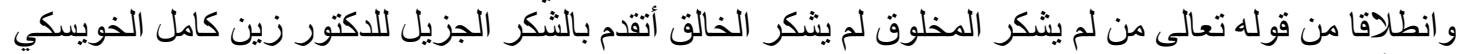

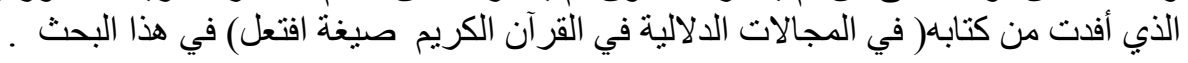
خلص البحث إلى جملة من النتائج ،أهمها:

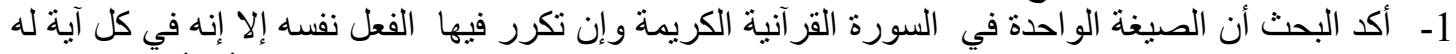

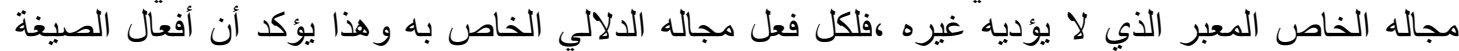

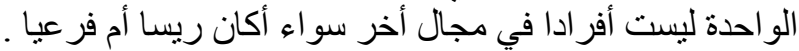
2- تتو عت المجلات ألتي احصيتها اعتمادا على تفسير ها عند مفسري القيان القرآ آن الكريم فكانت في البر و الإحسان

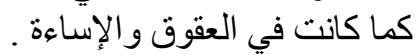
3- لكل عنو ان عام في المجلات الدلالية عنو انات فر عية تنضوي تحته. 


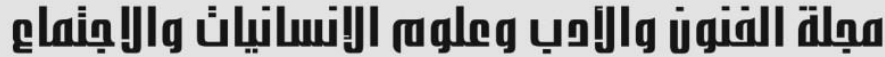

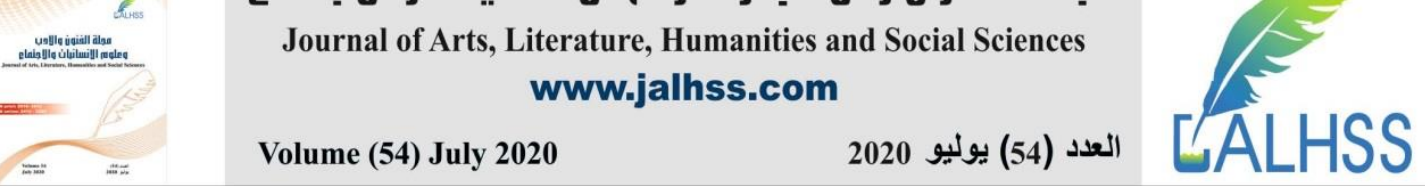

4- لم تقتصر الدلالة الصيغية على زمن دون آخر فقد وردت دالة على الزمن الماضي ،كما دلت على الزمن

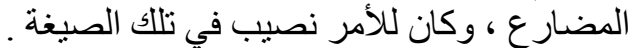
5- فكرة المجال الدلالي يمكن استثمار ها في كل مستويات اللغة :الصوتية ،و الصرفيه ،و النحوية ،و المعجمبة

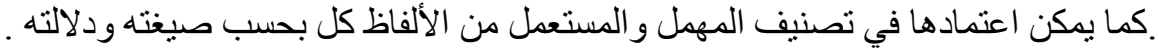
6- السياق له الأثر البالغ في توجيه دلالة الصيغة فلو تغير السياق لتغيرت الدلالة تبعا لذللك .

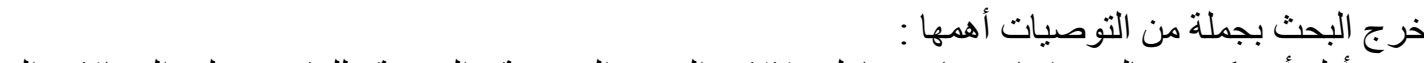

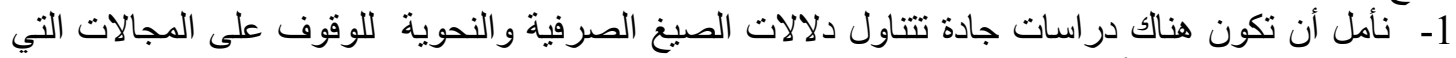

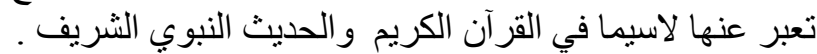
2- إن تطبيق هذه النظرية على تر اثنا الأدبي بشقيه الثعري و النثري له أهمية كبرى في رصد الألفاظ ومعانيها وتبويبها .

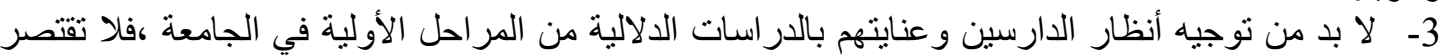

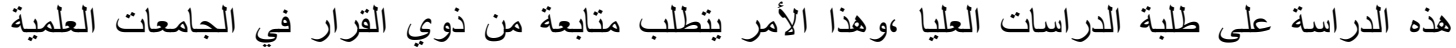

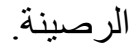
4- قر اءة تر اثنا العربي قر اءة دقيقة و الوقوف على ما أودع من أسر ار لكثفها وتنظير ها قبل غيرنا .

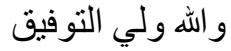

\section{الهوامش}

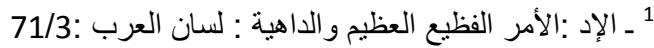

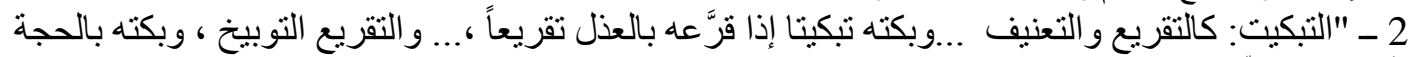

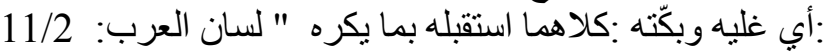

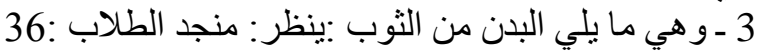

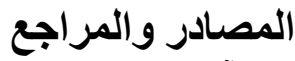

1- الآلوسي : شهاب الدرابع الدين أبو الثناء ،(1415هـ) روح المعاني في تفسير القرآن العظيم والسبع المثناني،(1)

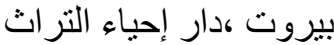

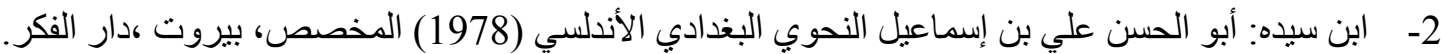

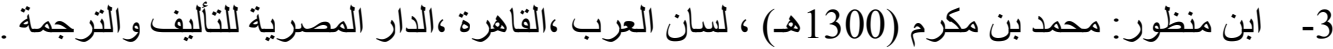
4- - الأندلسي الغرناطي: أبو حيان محمد بن يوسف (1978) تفسير البحر المحيط (ط2) بيروت ،دار الفكر

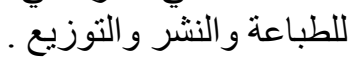
5- الجوزي: جمال الدين أبو الفرج عبد الرئ الرحمن بن علي بن محمد ، (1422هـ)زاد المسير في علم التفسير ،

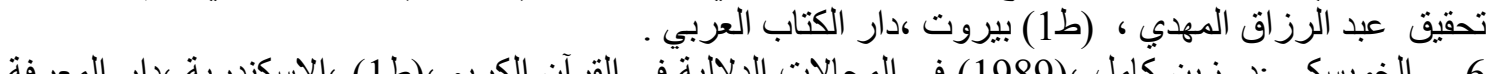

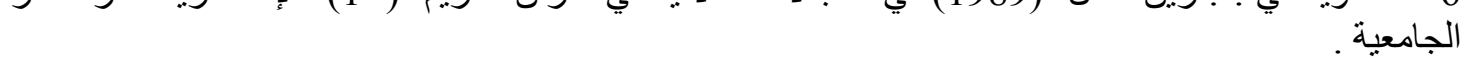
7- الر ازي: محمد بن عمر (1938) التفسير الكبير أو (مفاتيح الغيب)، ،(ط1) القاهرة ،المطبعة البهية المصرية.

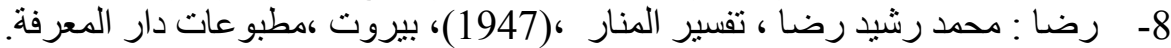

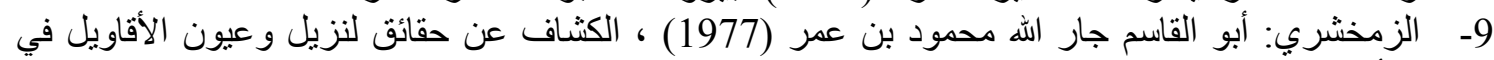
وجوه التأويل (طُ1)،بيروت ،دوار الفكر للطباعة والنشر. 10- زوين:د. علي عبد الحسين، (1992) المجال الدلالي بين كتب الألفاظ و النظرية الدلالية الحديثة بغداد ، مجلة

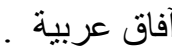
11- شبر : عبد الله (1999) ، تفسير القرآن الكريم ،(ط10) بيروت ، الدار الإسلامية . 


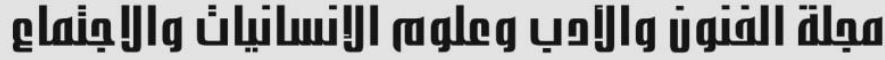

Journal of Arts, Literature, Humanities and Social Sciences

www.jalhss.com

12- الطباطبائي: محمد حسين (1429 هـ.) ،مختصر تفسير الميزان (ط1) ترتيب كمال مصطفى شاكر ، بيروت ،

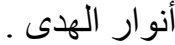

13- الطبرسي: أبو علي الفضل بن الحسن( 1379هـ) ، مجمع البيان في تفسير القرآن ،وقف على على تصحيحه

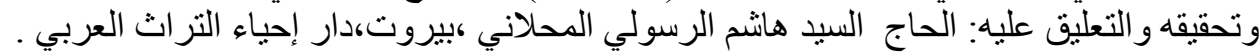

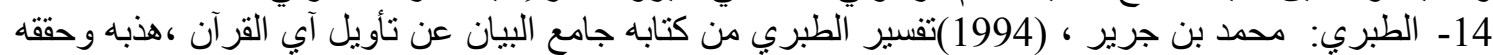

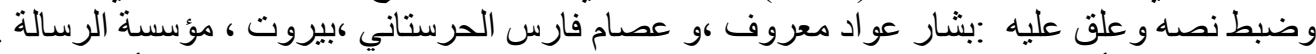

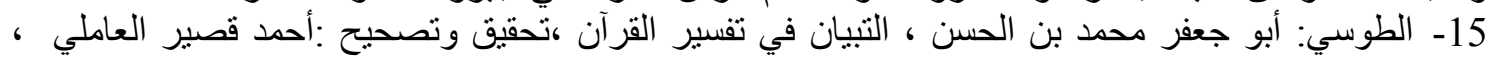

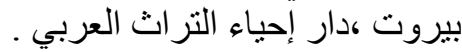

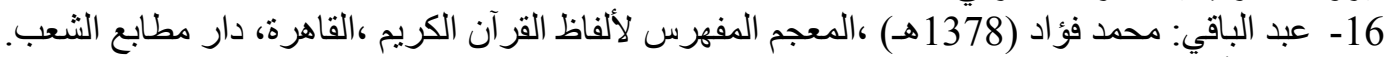

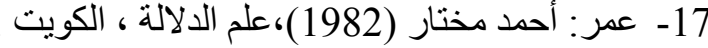

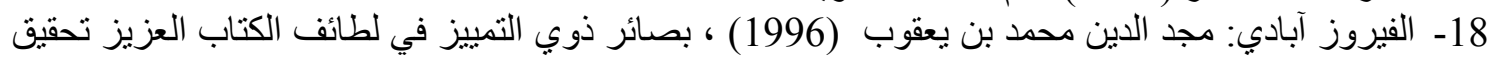

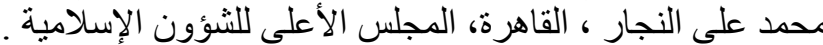

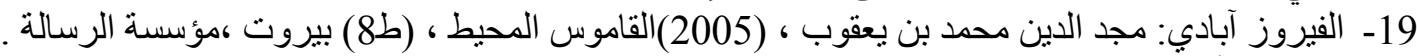

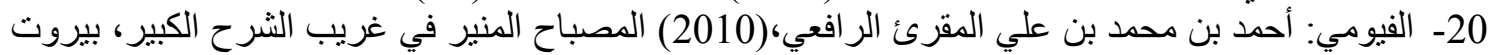

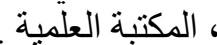
21- القرطبي: أبو عبد الله محمد بن أحمد بن أبي بكر شمس الدين ، (1964)تفسير القرطبي = الجامع لأحكام

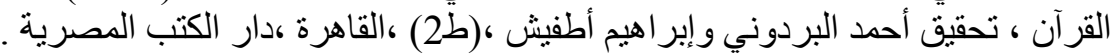

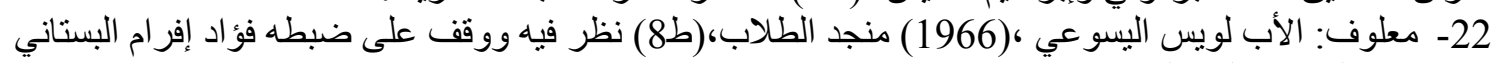

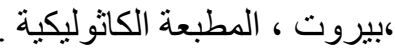
23- الواحدي: أبو الحسن علي بن أحمد (1415هـ)، الوجيز في تفسير الكتاب العزيز ، تحقيق صفوان عدنان

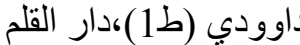

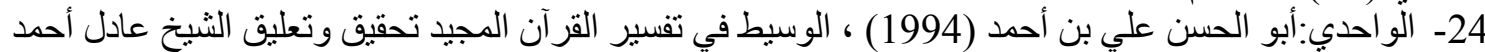
عبد الموجود و آخرين ، قدمه وقرظه الأستاذ الدكتور عبد الحي الفرماوي ،(ط1)،بيروت، دار الكتب العلمية. 


\section{References}

1- Al - Alusi: Abu Al-thanaa Shehab Addin(1415H) THE Spirit of meanings in interpreting hdy Quran and seventh seconds, (1pr.)Bierut the hovse of revivah heritage.

2- Ibk Sada: Abu Al - Hasan Ali Bin Ismaiel Al-Nahwy Al - Baghdadi Al-Andalusi(1978) speclolist, Bierut, Al-Fikr house.

3- Ibn Manthoor , Mohammad Bin Makram(1300H), Arab longue, Cairo, Egyption house for writing and translation.

4- Al-Andalusi Al- Gernati : Abu Hayan Mohammad bin yousif(1978) the interpretation of surrounded,sea(2pr.) Bie,rut, the house of thinking and printing.

5- Al- Jawzi : Jamal Alddin Abu Al- Faraj Abdul Rahman Bin Ali Bin Mohammad(1422H) (Zad Al- Maseer Fi eilm al- tafseer),achieved by: Abdul Razaq Al-mahdi (1.pr.) Bieruit, the house of Arabicbook.

6- Al- Kh awasky : Dr. Zain Kamel (1989) in semantic Fields of holy Quran(1.pr.) Alex , the houseof universal Knowleage.

7- Al-Rszi: Mohammad Bin Omar(1938) the big interpretation or (Mafateeh Al- gayb) (1.pr.) , Cairo Egyption Al- Bahaia print.

8- Ridha : Mohammad Rasheed (1947) Al-Manar interpretation, Bierut, Knowledge house printing.

9- Al - Zimakhshary : Abu Al- Qasim jar Allah MahmoodBin Omar (1977) Al Kashaf an haqayq tinazeel elwoon Al-aqaweel fi wijooh Al-taweel (1.pr.) Bierut, Alfikr housefor printing. 10- Zwain :Dr. Ali Abdul Hussein (1992) the semantic field between book of words and modem semantic phenomenon, Baghdad Arabic Afaq journal.

11- Shubr :Abdulloh (1999)interpretation of holy Quran , (10.pr.) Bierut ,Islamic house.

12- Al-Tabatabaie, Mohammad Hussein $(1429 \mathrm{H})$ the summary of interpretation AlMezan, (1.pr.),the order of Kamal Mustafa shaker, Bierut,Al- Huda lights.

13- Al- tibrsi:Abu Ali Ai Fadhil Bin Al- Hasan (1379H), the collection of Al-Bayan in in terpretation of holy Quran, achieved and correction dy: Al-haj Al- said Hashim $\mathrm{Al}$ Rasoli Al Mahalati , Bierut, the house of revival heritage.

14- Al- Tabri :Mohammad Bin Jarir (1994) Al- Tabri in terpretation from his book (the collection of Al- Bayan) achieved by: Bashar Awad Maaroof and Esam farsAl- khirsani, Bierut, Al- Resala organization.

15- Al- Tawsi : Abu Jaafar Mohammad Bin Al- Hasan , Al-Tibyan in interpretation holy Quran, achieved by:Ahmad Qaseer Al- Amily, . Bierut ,the house of revival heritage.

16- Abdul Baqi: Mohammad Fouad $(1378 \mathrm{H})$ the dictionary of Quran terms, Cairo, the house of people printing.

17- Omar: Ahmad Mukhtar(1982)semountic Kuwait.

18- Al- Fayroz Abady ,Majd Addin Mohammad Bin Yacop(1996) Basaier thawi Altameez fi Lataif Al- Kitab Al-Aziz ,achieved by: Mohammad Ali Al- Najar ,Cairo ,high boordfor Islamic affairs .

19- Al- Fayroz Abady ,Majd Addin Mohammad Bin Yacop(2005), surrounding dictionary(8.pr.), Bierut, Al-Resala organization.

20- Al-Fayomi : Ahmad Bin Mohammad Bin Ali Al-Muqrea Al-Rafie(2010) Al- Mesbah Al- muneer fi Goreeb Al -sharh Al- Kabeer, Bierut, scientic library. 


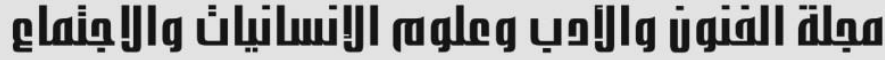

Journal of Arts, Literature, Humanities and Social Sciences

www.jalhss.com

Volume (54) July 2020

العدد (54) يوليو 2020

21- Al- Qurtubi : Abu Abdullah Mohamad Bin Ahmad Bin Abi Bakr shams Addin ,(1964), Al-Qurtubi interpretation( Al-Jamea li Ahkam Al- Quran, achieved by: Ahmad AlBardony and Ibraham Atgesh(2.pr.),Cairo, the house of Egyption books.

22- Maalof: Luise yasso Father(1966) ,Munjid Al-Tulab,(8.pr.)corrected by :Fouad Efrom Al-Bustani,Bierut,Catholik printing.

23- Al- Wahdy: Abu Al- hasan Ali Bin Ahmad(1415H) Abstract in interpretation Al-aziz book,achieved by: safwan Adnan Dawoody(1.pr.) Al-qalam haos .

24- Al- Wahdy: Abu Al- hasan Ali Bin Ahmad (1994) Al- Waseet fi tafseer Al-Quran, achieved by : sheikh Adel Ahmad Abdul mawjood and others, presented by :prof.Dr Abdul Haee Al-faramawei(1.pr.),Birout, scientific books house. 